\title{
La navegación en el mundo antiguo. Mercantes fenicios y cartagineses
}

\author{
VICTOR M. GUERRERO AYUSO \\ Departamento de Ciencias Historicas \\ Universidad de las Islas Baleares
}

No parece ocioso dedicar una jornada de este symposium sobre Melilla $y$ su entorno en la Antigüedad a intentar una aproximación al conocimiento de los navios, que desde la fundación de la Rusaddir fenicia debieron frecuentar sus costas al abrigo de su puerto y del cabo y promontorio Metagonion.

Las fuentes literarias no dejan lugar a dudas de la importancia de Rusaddir y el Metagonion en las navegaciones hacia las Columnas de Hércules. Nos faltan evidencias arqueológicas de los momentos fundacionales de la ciudad, sin embargo, dado el carácter estratégico en las rutas de navegación, no dudamos de que la frecuentación de sus costas se debió de producir desde el momento mismo en que se consolidan las navegaciones fenicias al Extremo Occidente. En este contexto, tal vez sea conveniente recordar que los fenicios no inauguran las comunicaciones ultramarinas del Oriente y / o Egeo con Occidente. Durante muchos años las aventuras de Odiseo en las tierras aledañas a las Columnas de Hércules no tenían otra entidad que la legendaria. Sin embargo, la presencia de cerámica micénica en el Llanete de los Moros (Martín de la Cruz, 1987; 1988; 1994), en Puru- 
Llena, Granada (Molina, F. / Pareja, E., 1975) y la presencia de influencias claramente egeas y / o anatólicas, como el altar de cuernos de la consagración de la Encantada (Sánchez Meseguer / Fernández Vega / Galán / Poyato, 1980) en contextos indígenas del último tercio del segundo milenio a. C., no dejan lugar a dudas de que las navegaciones a Occidente son muy antiguas. Seguramente los fenicios no hicieron otra cosa que apropiarse de rutas de navegación ya conocidas y aprovechar redes indígenas de intercambio marino para integrarlas en el tráfico comercial a larga distancia que a partir del primer milenio a. C. sin duda alguna dominan.

Si estos indicios arqueológicos, algunos ya datos bien sólidos, los contrastamos con las necesidades que en cuanto a las derrotas de los navíos imponen vientos y corrientes en esta zona del Estrecho (Alvar, 1981; Fernández-Miranda, 1988; Ruiz de Arbulo, 1990; Guerrero, 1994; Diez Cusi. 1994) no parece exagerado pensar que las costas de la futura Rusaddir fenicia hayan sido igualmente frecuentadas a lo largo de ese oscuro e impreciso periodo, aunque no menos real, que muchos investigadores vienen denominado "precolonización".

Todas las culturas con base económica marinera disponen de una variada gama de modelos náuticos para cubrir distintas necesidades, desde pequeñas barcazas auxiliares hasta grandes mercantes, pasando por la marina de guerra. Por ello conviene aclarar que sólo nos ocuparemos de los dos tipos básicos de navíos que jugaron una papel crucial en la expansión colonial fenicia: 1) El gaulos, mercante de gran tonelaje y pieza clave en los transportes masivos de mercancías. 2) El hippos, barco ligero, polivalente y protagonista de las exploraciones precoloniales.

La documentación básica sobre la que se sustentará esta exposición es principalmente la iconográfica. Las fuentes arqueológicas son escasas, dispersas y sólo en algún caso, como en la marina cananea, nos proporcionarán información relevante. Las fuentes literarias para el estudio de la marina fenicia son también muy exiguas y de nula validez a la hora de informarnos sobre la arquitectura naval. Sin embargo, son de un excepcional valor los relatos náuticos que nos proporciona la Odisea. En general nos ilustran el funcionamiento y utilidad del navío que conocemos como hippos. 
LOS GRANDES MERCANPLS: EL, GALLOS FEN IA MARINA CANANEA

(II" MILENIOA.C.)

Desde principios del siglo XIV a. C. la marina cananea está perfectamente desarrollada para llevar a cabo grandes empresas comerciales ultramarinas. Por lo que sabemos hasta hoy, su actividad quedó circunscrita al Oriente Mediterráneo. Sin embargo, pensamos que ya disponía en estos momentos de suficiente capacidad técnica como para llegar al Extremo Occidente. Paradójicamente tenemos más y mejor documentación para el estudio de la tecnología náutica sirio-fenicia de mediados del segundo milenio a. C. que para épocas posteriores.

Contamos con la documentación arqueológica que nos proporcionan las excavaciones de los pecios de Gelidonia y Ulu Burum y ésta, a su vez, puede ser contrastada con las fuentes iconográficas procedente de las pinturas de Tebas. A todo ello podemos añadir alguna documentación epigráfica complementaria contenida en los textos de Ras-Shamra / Ugarit.

EL GALLOS CANANEO EN LAS FITNTES LITERARIAS

Al hablar de la marina cananea no debemos olvidar la existencia de los navíos mercantes para transporte fluvial. Algunos textos de Ugarit (Vita, 1995:160) nos atestiguan la presencia de barcos cananeos fondeados en Karkemis (RS-34.147 y 00-4.779) para navegar por el Eufrates. También tenemos constancia (RS-20.162) de la presencia de barcos cananeos en Amurru, así como otros (RS-19.46) que navegaban por el Orontes (Vita. 1995:160). Los barcos ugaríticos de Karkemis debieron ser forzosamente construidos y botados en el mismo río Eufrates, pues no existe conexión fluvial con el país de Canaan. Tal vez pudieron ser naves de juncos como las que habitualmente navegaban por los ríos mesopotámicos. No tenemos información iconográfica para intentar una reconstrucción de estos navios, aunque pensamos que no debían diferir sensiblemente de las barcas de juncos que conocemos a través de los grabados nubios (Resch, 1967).

Un texto ugarítico (00-4.421) refiriéndose a un barco grande (o real) emplea el término ' $t k$ de etimología insegura, aunque en ugarítico existe el 
verbo 't $k$ con el significado de atar, ligar (Vita, 1995:167). Lo cual puede ser otro indicio de que estamos ante embarcaciones cananeas de juncos, pues como es sabido la construcción de este tipo de barcos requiere una especial pericia en el ligado de los juncos para que la nave no se deshaga al navegar. La interpretación puede ser coherente en el contexto de las navegaciones fluviales mesopotámicas. Sin embargo, debemos recordar que también los barcos de madera pueden estar construidos mediante la ligazón o cosido de las tablas y cuadernas. Esta técnica está bien documentada en la nave etrusca de Bon-Porté (Basch, 1976) y muy recientemente se ha podido comprobar que los barcos fenicios del siglo VII a. C. hundidos en la ensenada de Mazarrón (Negueruela, 1996) estaban construidos con una técnica mixta que combinaba el cosido de tracas y cuadernas con el sistema de ensamblaje mediante espigas y pasadores.

Para el estudio de los grandes mercantes cananeos que afrontaban complejas empresas comerciales por altamar tenemos afortunadamente una variada información que nos permite contrastar datos procedentes de documentación epigráfica, iconográfica y arqueológica.

Remitiéndonos de nuevo a los textos de Ugarit (Vita, 1995: 166-167), tres cartas permiten asegurar la existencia de barcos de gran registro. Una de ellas (RS 20.141), aunque muy fragmentada parece referirse a treinta grandes barcos. Otra, enviada desde la corte Hitita al rey de Ugarit y referida a un importante transporte de grano, menciona en la línea 21 un "barco grande" [MA $G A L]$. El cargamento se cifraba en 2.000 medidas de grano, que podría ser equivalente a $500 \mathrm{Tm}$., y debía realizarse en uno o dos viajes. Quizás se trate del tipo de barco conocido en ugarítico como $A N Y T$ YM, que algunos autores (Vita. 1995:166-167) traducen por barco grande o barco de ultramar.

La fuentes escritas no nos proporcionan datos útiles para conocer la arquitectura naval, sólo nos permiten certificar la existencia de flotas compuestas por numerosos navíos, algunos de los cuales eran sin ninguna duda mercantes de gran registro bruto. Parece que en estas complejas empresas comerciales participaban siempre navíos organizados en flotillas y nunca solos. La existencia de esta organización puede remontarse hasta el tercer 
milenio a. C., cuando tenemos noticia de una flota compuesta por cuarenta naves cananeas que transportan cedro a Egipto (Aubet, 1994:154).

Sólo un texto administrativo (00-4.689) nos da algunas pistas sobre elementos de la estructura de los navíos cananeos. Enumera componentes de un barco ugarítico que estba fabricado por HRS ANYT, "carpinteros de barcos”. La traducción propuesta (Xela, 1982; Vita. 1995:167) es la siguiente:

\section{Lista de equipamientos de la flota \\ 2. Nueve remos \\ 3. Como nueva entrega \\ 3a. \\ 4. Y una cofa de rejilla \\ 5. Un mástil, amarras, \\ 6. y una pasarela...}

No obstante, la epigrafía nos proporciona datos complementarios que otras fuentes de documentación nunca aportan. Así: algunos textos (00-4.40 y RS-19.46) nos ofrecen información sobre el reclutamiento de las tripulaciones y sus lugares de origen. Las líneas décima a decimoctava nos indican que la tripulación de un mercante cananeo podía estar compuesta de unos dieciocho marineros (Vita, 1995:170). En otros textos, que se refieren a naves comerciales, se mencionan al menos dos títulos que pueden interpretarse como oficiales, cargos que en ningún caso serían de naturaleza militar, aunque ocasionalmente pudieran participar en acciones bélicas (Vita, 1995:172). Uno de estos títulos es RAB MALAHI (RS-17.133:15) equivalente a jefe de los marineros o supervisor de los marineros. El otro es RB TMTT (00-2.38) que puede traducirse por jefe de la dotación, jefe de la tripulación o capitán (Vita, 1995:172). A todo ello podríamos añadir también el título de patrón o armador que parece deducirse de la traducción del término $S B U A N Y T$ registrado en el texto administrativo 00-4.40 (Vita, 1995:161). El oficio de carpintero de ribera o carpintero de barcos aparece registrado en el texto 00-4.125:1 bajo la denominación de HRS ANYT (Vita, 1995:161). 
Las fuentes literarias nos certifican de forma incuestionable la participación de la flota ugarítica en acciones de guerra, casi siempre en colaboración con Hatti (Vita, 1995:174-176). Sin embargo, no podemos contrastar esta información a partir de la iconografía náutica. Tal vez debamos pensar que se trata en realidad de barcos mercantes ligeros o semiligeros; como el de la tumba de Nebamun o los que acompañan a la flota mercante de Kenamon, empleados para el trasporte de tropas, armas, víveres, etc., pero no en función estrictamente militar, entendiendo ésta como batalla naval. A fines del segundo milenio a. C. parece que sólo Egipto había diseñado y construido navíos específicos para la batalla naval. Los relieves de Medinet Habu (Nelson, 1943) nos muestran la flota de guerra de Ramses III en la batalla del Delta (1186 a. C.) enfrentada a los barcos de los "pueblos del mar" (Wachsmann, 1981; 1982). Mientras que los marinos egipcios tripulan naves de quilla seguramente monóxila, muy ligeras y con una proa rematada en lo que podría considerarse como un precedente del espolón, los barcos de los pueblos del mar son en realidad mercantes semiligeros que recuerdan mucho la estructura de los hippoi que más adelante veremos.

\section{IA ICONOGRAFIA NAUTICA DIL G GULLOS CANANEO}

Básicamente procede de las pinturas sepulcrales de la necrópolis de Tebas, por lo tanto, de lo que disponemos es de la interpretación egipcia de los mercantes cananeos. Afortunadamente podemos compensar la falta de información directa cananea con la meticulosidad y espíritu narrativo y detallista de los artistas egipcios. En la tumba de Nebamun pudo reconstruirse (Säve-Söderbergh, 1957) una pintura en muy mal estado de conservación (figura 1) que representa un mercante cananeo, probablemente de mediano porte. Roda y codaste aparecen elevadas y de hechura muy similar. La nave va aparejada con una vela cuadra entre dos vergas, sobre un mástil con cofa cuadrada, que parece ser un elemento de identidad típico de las naves cananeas, pues la cofa de las egipcias es siempre de base redonda. La jarcia está escasamente representada y sólo se pueden distinguir con claridad la burda y los amantillos para izar y arriar la verga. E] 
estay queda tapado por la vela y sólo se aprecia su arranque en la base de la roda, tapado por el marinero que porta una especie de bastón de mando. Es difícil de interpretar qué trabajo debían realizar los cabos que partiendo de la base de la cofa por un chicote se afirman en los penoles de la verga por el otro. No se ha representado parte de la jarcia de labor que es

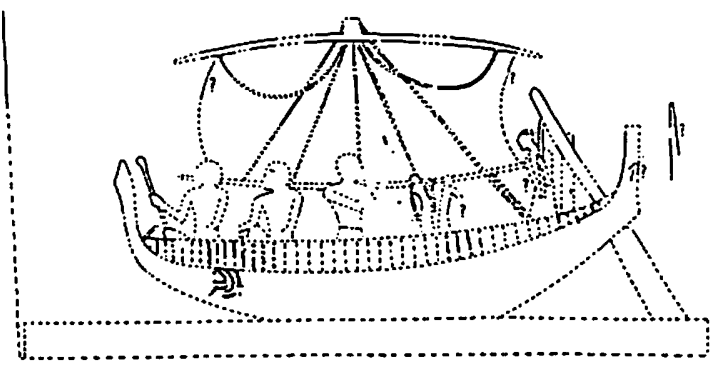

FIC:Itis 1 Pintura de la cuuba de. Nebamen isentios save-sielerluerght; fundamental en el manejo del velamen, como son las brazas y las escotas.

El gobierno de la nave se ejerce mediante un timón de espadilla que maniobra por la aleta de estribor, sujeto a una percha y accionado por el timonel mediante un travesaño. Como en todos los mercantes cananeos, la borda va realzada por una falca o escalamote que permite ir en cubierta con más seguridad. Los marineros, a excepción del timonel que está de pie, van sentados en cubierta seguramente sobre vancadas. Lo que nos hace pensar que efectivamente se trata de un mercante ligero o de mediano porte, tal vez sin bodega, a diferencia de los grandes mercante que veremos ahora en la tumba de Kenamon.

Mejor conservadas en el momento de su descubrimiento (Davies / Faulkner, 1947) estaban las pinturas de la tumba 162 de Tebas, perteneciente un alto dignatario de la XVIII dinastía y responsable de los graneros del templo de Karnak.

Este personaje se hizo representar en su tumba una secuencia (figura 2) dividida en distintos registros que seguramente resumen lo que debía ser la actividad habitual de su cargo, es decir la recepción de las flotas mercantes y la fiscalización de las entradas de productos en el templo. Las pinturas parecen relatar una secuencia completa, con distintas escenas, que van desde el instante en que los barcos divisan tierra en alta mar, hasta que llegan a puerto, se amarran las naves y se procede al intercambio de mercancías. 
El primer registro (figura 2a), que ocupa un tercio aproximado de toda la secuencia, es una escena que nos presenta tres naves: dos grandes mercantes idénticos y una tercera de casco algo más plano situada detrás, que seguramente se trata de una nave de apoyo a la flota, o de un mercante ligero próximo al que hemos visto en la tumba de Nebamun, tal vez próximo al modelo náutico que conocemos como hippos. Los barcos navegan aún, así lo indican las velas desplegadas e hinchadas por el viento con marcadas balumas. Las palas de los gobernáculas no se ven al quedar bajo la superficie del agua, a diferencia de lo que ocurrirá cuando las naves estén atracadas al muelle. La actividad que desarrolla la tripulación nos indica también claramente que están aún en alta mar, aunque seguramente se ha divisado ya la costa a la que se pretende arribar. En efecto, en la cubierta de la nave pueden distinguirse dos categorías de marinos, identificados según el conocido canon egipcio de representar a los personajes de mayor categoría jerárquica con un tamaño superior. Así pues, los tripulantes de pelo largo y barba puntiaguda vestidos con lujosas ropas, ceñidas con amplios cinturones, que les cubren el cuerpo entero, deben ser mercaderes cananeos. Los otros personajes, representados en menor tamaño, rapados y vestidos sólo con un faldetín corto, deben ser marineros, tal vez siervos o esclavos.

Uno de los comerciantes está de pie, subido en la roda y parece dirigir la palabra al resto. El comerciante situado en lugar central, próximo al mástil y encarado a la proa, mantiene en sus manos una copa de altísimo pie, ¿micénica?, con la que parece querer efectuar una libación. Otro comerciante, delante del anterior, agarra con sus manos un ánfora cananea y se inclina mirando su interior, de donde seguramente se ha extraído el líquido, con toda probabilidad vino, que llena la copa de su compañero. El resto de los comerciantes alzan ambas manos con las palmas al frente, en clásica postura de acción de gracias.

Los marineros están dedicados a tareas propias de preparar los aparejos para la llegada a puerto. Sólo dos alzan sus manos también en acción de gracias, son los que se encuentran encaramados sobre el mástil, seguramente en una cofa cuadrada que por la posición de la vela no se ve, la cual 


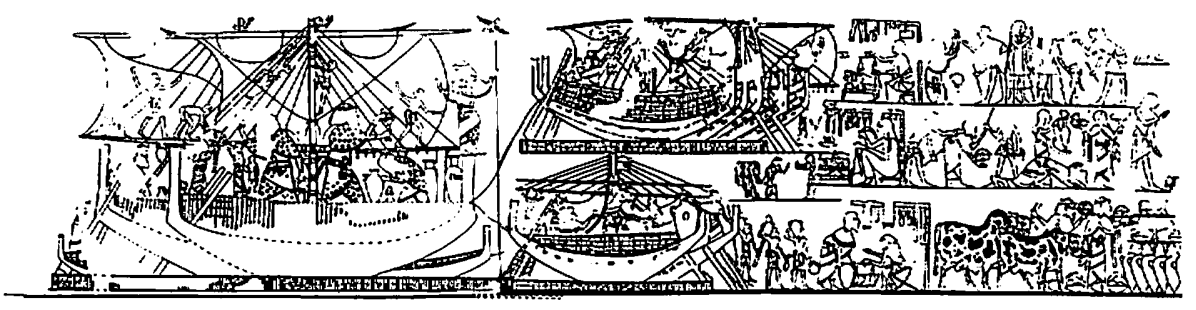

Hallat

Pinturns do In turnha de: Kimarum, senencin completa (sipúu Davits / Faulkner).

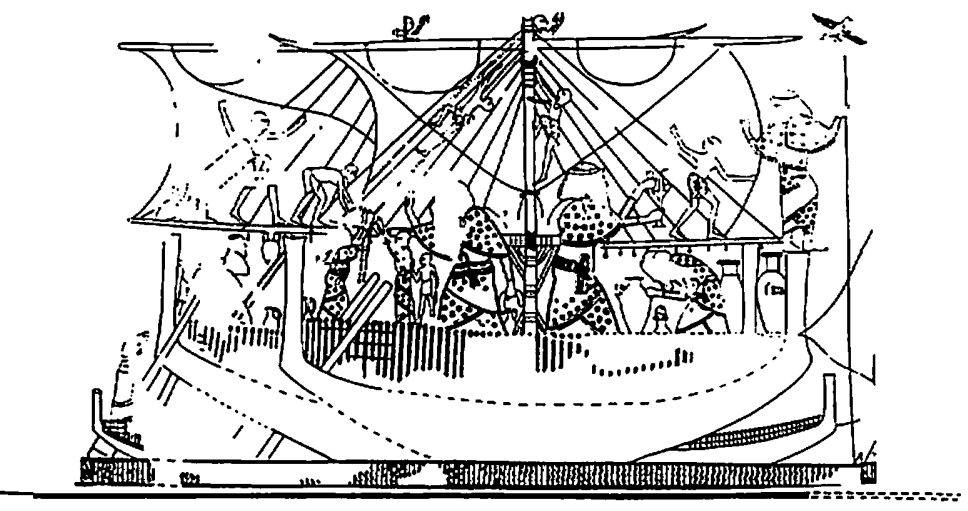

Fll:111 :

Eicena en altauar.

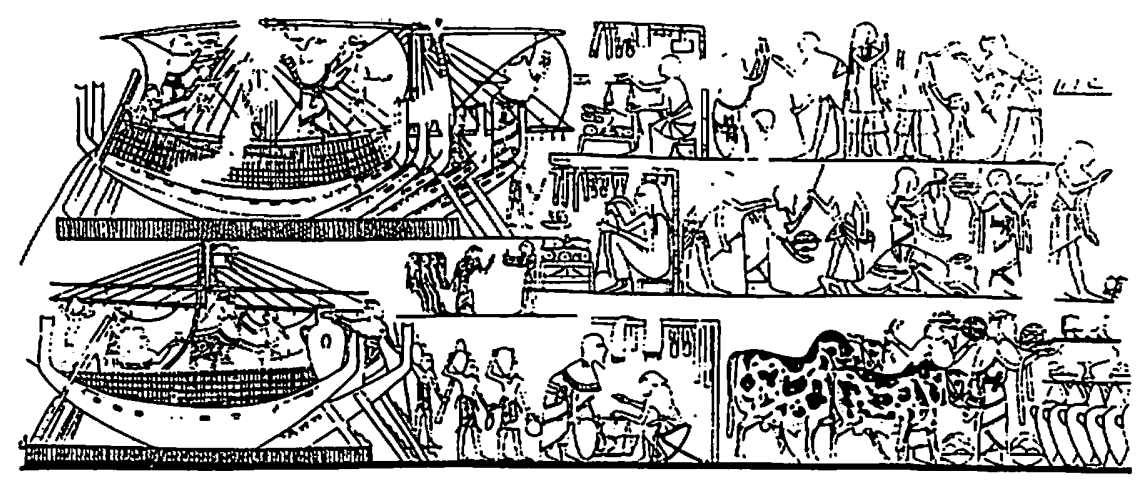

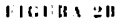

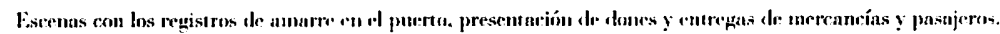


se puede observar en la escena con las naves en puerto y las velas arriadas. Tal vez se trata de los vigías de turno. Otros marineros caminan encaramados en la verga inferior. Uno trepa por un briol (o un amantillo) de la verga. Del extremo superior de la escena parte un ave volando con el mismo rumbo que las naves. Posiblemente el artista quiso dejar constancia del sistema habitual de la época para orientarse y buscar tierra en alta mar, es decir soltar aves y seguir su rumbo (Hornell, 1946; Luzón / Coin, 1986; Guerrero, 1994:19-26).

En estos momentos en los que los barcos aún navegan, puede apreciarse con precisión el conjunto de los aparejos trabajando. En realidad son idénticos a los egipcios, o tal vez para ser más justos deberíamos decir que los egipcios adoptaron los mismos aparejos, seguramente asesorados por técnicos cananeos. Un único mástil soporta una vela cuadra entre dos vergas que se recogen mediante los brioles, muy bien representados, éstos trabajan desde la pieza ondulada con groeras y motones ligada a la parte superior del mástil, muy similar a la que vemos en las naves del Punt (Säve-Söderbergh, 1946), o en la nave de la tumba de Tutankhamun (Jones, 1995:50-51). De los penoles de la verga superior parten dos brazas que están amarradas al mástil. No se pueden apreciar los amantillos de la verga superior, pero debía tenerlos, pues es el sistema habitual para sostenerla. Entre la jarcia mayor pueden distinguirse dos gruesas burdas en uno de los navíos, a los que debían corresponder otros dos estays por proa, que no se ven ocultos por las velas. Las naves disponían también de una escala de gato para subir a la cofa.

La fisonomía del casco es el habitual de las naves mercantes, curvo y panzudo, aunque el artista los estiliza. Proa y popa son idénticas y un timón de espadilla situado en la aleta de estribor sirve al gobierno de la nave. La borda está realzada por un escalamote de tablillas o cañizo en forma de baranda protectora, como ya habíamos visto en la nave de $\mathrm{Neba}$ mun. Landström (1983:31, fig. 62) hace una interpretación (figura 4a), a nuestro juicio, desacertada del escalamote, lo sitúa retirado de la borda para dejar sitio a los bancos de los remeros. La cuestión está en que no creemos que la propulsión de las naves mercantes sea a remos. Tal vez el 


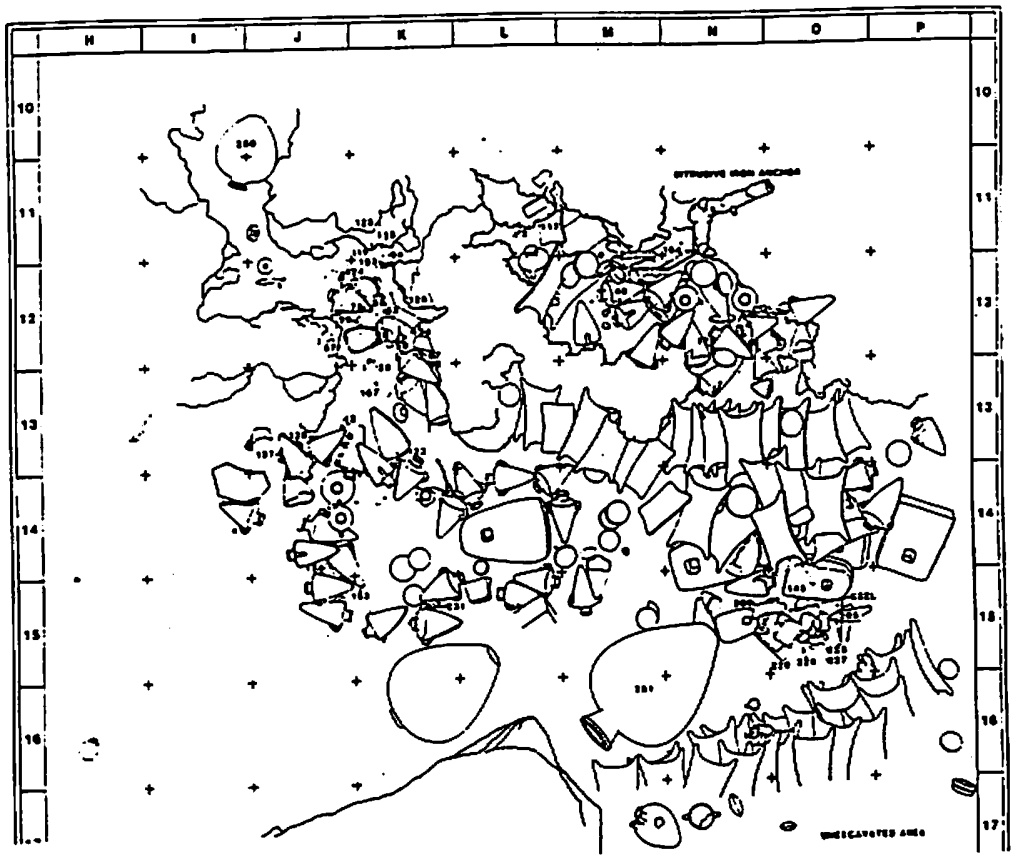

Fi:lal

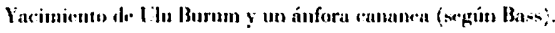

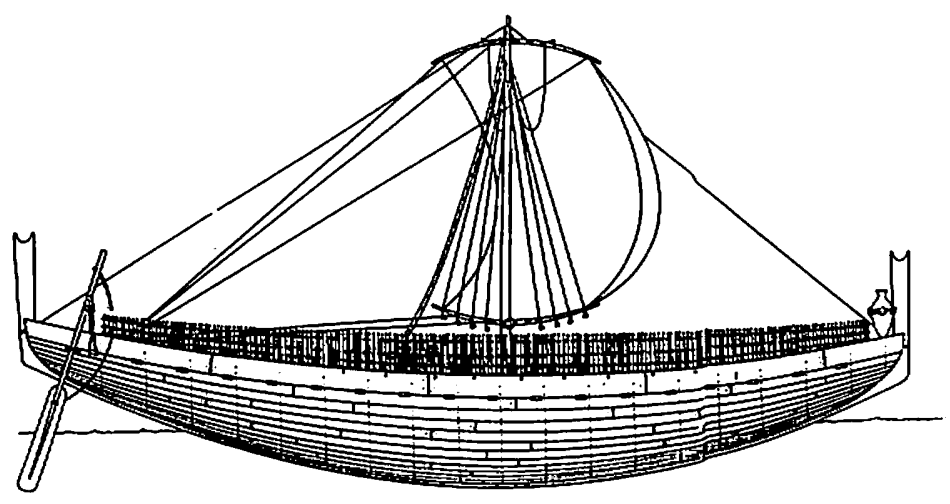

Ticil R. +h

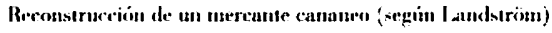


error arranca de considerar mercantes las naves de casco redondeado que evacuan al rey Luli de Tiro, como algunos investigadores (Alvar, 1981; Graeve, 1981:128-131; Gras / Ruillard / Teixidor, 199:100; Aubet. 1994:43) han argumentado sólo basándose en su forma simétrica y redondeada, por contraposición a las que van provistas de espolón. Sin embargo, no puede pasarse por alto que tanto unas como otras son birremes y como sabemos, es difícil compaginar los dos niveles de bancos en un navío destinado exclusivamente al comercio. Los mercantes podían disponer de un número reducido de remeros para maniobrar o salvar una emergencia, pero en ningún caso dos órdenes de remeros. Toda la documentación arqueológica submarina disponible sobre mercantes antiguos corrobora esta tesis, y la iconografía de naves exclusivamente mercantes tampoco registra la presencia de remeros, mucho menos birremes.

La estilización convencional de las pinturas de la tumba de Kenamon no nos puede ocultar la existencia de una bodega de carga de gran capacidad. La presencia de bodega no sólo es evidente a partir de las mercancías que se desembarcan, ánforas, pithoi y eventualmente bueyes, además de algunos pasajeros, todo no podía ir en cubierta como es obvio. Sin embargo, el detalle más clarificador en este sentido es que el artista no olvidó, pese a la estilización convencional del casco, reproducir las cabezas de baos o sobrebaos, que es la pieza de arquitectura náutica imprescindible en una nave con bodega cubierta. En las pinturas mejor conservadas se pueden contar hasta 15 cabezas de baos que sobresalen en los costados de las naves, bajo la borda. Alguien podría interpretarlos como imbornales, sin embargo el destino de los imbornales es el procurar el rápido desagüe del agua embarcada en el cabeceo de la nave y se sitúan justo en la línea de la cubierta, por lo que, a los efectos que aquí nos interesa, también si fuesen imbornales estarian indicándonos que se trata de naves con bodega cerrada por cubierta. De todas formas creemos que la interpretación correcta de este elemento es el de cabeza de bao, la prueba más evidente es que en las naves del Punt aparece representado en relieve.

La documentación arqueológica de los baos, sobrebaos, durmientes. etc., como todos los elementos de la obra muerta del navío, se pierden 
tras el naufragio y es muy difícil su estudio. Excepcionalmente conservamos un caso referido a una nave tardoromana (Gassend / Liou / Ximenes, 1984) que nos puede servir para ilustrar estos elementos de la arquitectura naval antigua y contrastarlos con la documentación iconográfica que, pese a su tratamiento idealizado y convencional, es a veces de una rigurosidad asombrosa.

Todas las naves de Kenamon llevan un ánfora amarrada por las asas a la parte interior de la roda, tal vez sirviesen para mantener un sistema de iluminación que les permitiese maniobrar por la noche en cubierta y eventualmente señalar su posición cuando se navega en formación, como así parece que debía ocurrir normalmente. Un ánfora taladrada y cortada al efecto hallada en el río Herault se ha considerado efectivamente como un sistema de iluminación nocturna (Fouquerle, 1973).

Por lo que respecta a las jarcias, las pinturas de esta tumba nos ofrecen un panorama bastante más completo que la de Nebamun. Entre la jarcia de labor se distingue perfectamente los amantillos, que en número de catorce, arrían o izan las vergas. También podemos identificar las brazas que descansan amarradas a media altura del mástil, por el contrario, no aparecen representadas las escotas, que con toda seguridad debían existir, pues son indispensables para el manejo de las velas. Volvemos a encontrar los cabos que aparecen por parejas amarrados a la verga superior. Están combados y, por lo tanto, sin tensar lo mismo con las velas izadas, que con ellas recogidas. Son los mismos que habíamos visto en la nave de Nebamun y cuya utilidad no podemos aclarar.

La información que nos proporcionan las pinturas de la tumba de Kenamon no se agotan en las cuestiones exclusivamente náuticas, como ahora veremos. La secuencia continúa en las escenas que recogen los registros de la derecha (figura $2 b$ ). La zona central, con dos registros superpuestos, está dedicada a las operaciones propias de la arribada a puerto de las naves, mientras que el extremo derecho de las pinturas, con tres registros superpuestos, recoge las escenas de los saludos, y de las operaciones comerciales.

La inmediata llegada a puerto se representa en la escena del registro superior central. Así lo indican detalles como las palas de los goberná- 
culas que ahora aparecen sobre la superficie del agua, las escalerillas que desde las amuras de babor descienden hasta el muelle, así como las velas aún desplegadas. Los comerciantes saludan desde cubierta y baja un personaje.

Por fin, en la escena del registro inferior central, las naves están definitivamente amarradas y preparadas para su permanencia en puerto, estancia, que como sabemos, podía ser larga. Recordemos al efecto la siguiente cita de la Odisea:

“... Quedáronse los fenicios un año entero con nosotros y compraron muchas vituallas para la cóncava nave..." (Od., XV, 493-495)

Las velas, como corresponde cuando el fondeo ha de ser largo, han sido recogidas, seguramente desmontadas y guardadas, las vergas aparecen por lo tanto sin velas, a media altura del mástil soportadas por los amantillos. Un marinero, subido en una cofa cuadrada, parece arreglar los amantillos de una de las vergas, otro desde la cubierta de popa sujeta la verga por el penol. Una fila de marineros descargan ánforas cananeas que llevan sobre en el hombro, mientras que portan objetos más ligeros en la mano libre.

La parte derecha de la escena, dividida en tres registros horizontales, recoge las actividades que se realizan en los muelles del puerto. Saludos entre comerciantes y dignatarios egipcios. Los mercaderes cananeos portan en las manos dádivas que ofrecen a los egipcios, sin la presencia de escribas que anoten su entrega. Esta acción podría interpretarse como la entrega de dones o bienes de prestigio, sin contrapartida económica inmediata, destinados a mantener buenas relaciones diplomáticas y comerciales.

Funcionarios egipcios sentados en actitud de pesar y anotar mercancías reciben las ánforas y otras mercancías de carácter comercial. Algunas entregas a los funcionarios egipcios revisten cierto interés, se trata del traspaso de dos mujeres y una niña que se efectúa en el registro superior. ¿̨Son pasajeros que aprovechaban el viaje de los cananeos para repatriarse?. La Odisea nos ofrece un pasaje que podría ilustrar esta situación: 
*... Me jacto de haber nacido en Sidón, que abunda en bronce, y soy hija del opulento Aribante. Robáronme unos piratas tafios un día que volvía del campo y, habiéndome traido aquí, me vendieron al amo de esa morada, quien les entregó un buen precio..." (Od., XV, 461-465).

‘... ¿Querrías volver a tu patria con nosotros...?

... Así lo hiciera si vosotros [los fenicios], oh navegantes, os obligaseis de buen grado y con juramento a conducirme sana y salva a mi patria..." (Od. XV, 461-474).

La presencia de pasajeros ajenos a la tripulación, y en especial mujeres queda bien reflejada en el siguiente pasaje que nos relata Herodoto:

... “Llegaron a Argos ... hicieron muestra de su carga; al quinto o sexto día de su llegada, vendido ya casi todo, concurrieron a la playa muchas mujeres, y entre ellas la hija del rey ... Mientras se hallaban las mujeres cerca de la popa de la nave, comprando las mercancías que más deseaban, los fenicios, exhortándose unos a otros, arremetieron contra ellas; la mayor parte escapó, pero Io fue arrebatada con otras; la llevaron a la nave y partieron, haciéndose a la vela para Egipto".

La actitud de las mujeres saludando al funcionario egipcio de la tumba de Kenamon podría remitirnos a una situación similar a la repatriación de la hija del rico Aribante. Sin embargo, en el tercer registro se representa una escena que sin duda debe referirse a la trata de esclavos: un comerciante cananeo hace entrega de varios hombres que van en fila, y seguramente maniatados, a un funcionario egipcio que anota la operación en una tablilla.

El registro inferior está íntegramente dedicado al traspaso de mercancías comerciales. Se inicia con el descenso de marinos que portan ánforas cananeas y otras vasijas, mientras un comerciante hace la presentación de la carga a un funcionario que sentado las reconoce y anota. Al final de este registro aparecen ya almacenadas y clasificadas las mercancías: en el suelo filas de ánforas cananeas, en los estantes intermedios otras vasijas y en el 
superior otros objetos valiosos como la estatuilla de un buey. Interesa destacar que entre las mercancías que los mercaderes fenicios entregan aparecen dos grandes bueyes que presumiblemente viajaban en las naves. La iconografía egipcia nos ofrece muchas muestras de animales que viajan en la cubierta de los barcos que era sin duda un transporte habitual en el Egeo, como podemos comprobar en los siguientes pasajes de la Odisea:

“... les mandé que cargaran presto en la nave muchas de aquellas reses de hermoso vellón..." (Od., IX, 470-494).

*... echamos al agua la negra embarcación, izamos el mástil y descogimos el velamen; cargamos luego las reses... asiendo las ovejas, anduvimos a lo largo de la corriente del Océano..." (Od. XI, 1-22).

“... Odiseo iba a cobrar una deuda de todo el pueblo, pues los mesenios se habían llevado de Itaca, en naves de muchos bancos, trescientas ovejas con sus pastores... A su vez, Ifito iba en busca de doce yeguas de vientre con sus potros, pacientes en el trabajo, que antes le habían robado..." (Od. XXI, 15-25).

Tal vez deberíamos incluir también entre las representaciones de gauloi del segundo milenio (1200-1075 a. C.) la nave pintada (figura 3) en una urna funeraria hallada en Hama (Ingohlt,

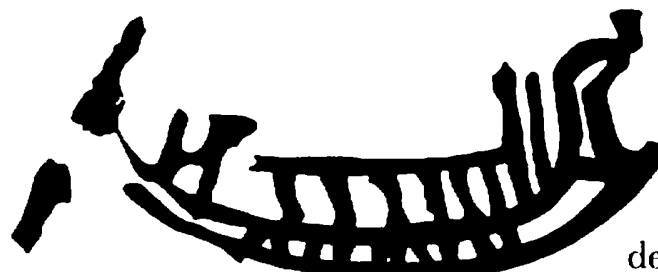
1940:pl.XXII:2), a orillas del Orontes. No conserva, o no se representaron los aparejos. Sin embargo, es perfectamente identificable la falca o escalomote típico de los grandes mercantes cananeos, y que los $111,1111,3$

hippoi no llevan nunca para dejar sitio a los toletes y chumaceras. Una roda, con un akroteria no identificable, se eleva recta sobre la proa, que con toda seguridad va provista de tajamar. Elemento cuya existencia no se ha podido constatar en los gauloi dos centurias más antiguos pintados en las tumbas de Nebamun y Kenamon. 
Falta saber si se trata realmente de una innovación de fines del segundo milenio, o si los artistas egipcios no repararon en este detalle, cosa poco probable dada la meticulosidad con se representaron otros aspectos mucho más secundarios. En cualquier caso algunos gauloi de principios del primer milenio a. C., como veremos en una de las terracotas chipriotas de Amathus ya lo tienen incorporado a la arquitectura naval, lo que sin duda debió de suponer una mejora sustancial en la seguridad y navegabilidad de los largos viajes ultramarinos. En la zona de popa parece disponer de un tambucho o casetón. Un gran gobernácula se sitúa en el eje de crujía, sistema frecuente en los barcos nilóticos, pero no tanto en los de ultramar. La curvatura del casco, las líneas verticales que lo cubren en su parte central como si fuesen ligaduras, así como la disposición del gobernácula, podrían indicarnos que estamos en realidad ante un gaulos de juncos, cosa que, como hemos visto en las fuentes literarias de Ugarit, no sería nada extraño en una pintura hallada en el Orontes.

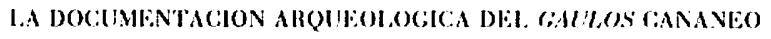

Pocas veces se tiene la fortuna de poder combinar en el estudio de la náutica antigua fuentes escritas, iconográficas y arqueológicas y: además, que estas sean relativamente contemporáneas. Esto ocurre precisamente con los mercantes cananeos de la segunda mitad del $\mathrm{II}^{\circ}$ milenio a. C. y ya no se volverá a repetir prácticamente hasta época romana.

Hasta el momento, dos son los barcos cananeos que han podido ser estudiados a través de la arqueología submarina: la nave de Gelidonya y la de Ulu Burum. La primera de ellas no conservaba el casco en condiciones de proporcionar una información relevante a los efectos del tema central que ahora nos ocupa. Sin embargo, la segunda está proporcionando una documentación sobre la arquitectura naval cananea extraordinaria y que viene a confirmar a grandes rasgos los estudios que hemos venido haciendo a partir de las fuentes escritas y de la iconografía náutica.

La nave de Gelidonya (Bass, 1967), cuyo descubrimiento y excavación tuvo lugar en la década de los años 50 por el equipo de C. Bass. Se hundió en la costa Sur de Turquía, no lejos del naufragio de la nave de Ulu Burum 
que después veremos. Por desgracia las estruturas del navío no se conservan en condiciones de estudio, que es el asunto principal que nos interesaba en este trabajo. Una parte importante del cargamento eran lingotes de cobre del tipo egeo, muchos de ellos con inscripciones emparentadas con los sistemas de escritura micénica Lineal-A y B. Las ánforas halladas son escasas y el único tipo reconocible es un ánfora cananea, cuya datación más alta estaría en torno a 1.350 a. C. y en cualquier caso sería anterior a las incursiones de los pueblos del mar. Otros restos de vasijas cerámicas pueden constituir parte de la vajilla de abordo, como varias jarras, un mortero y una vasija de piedra, etc.. Al igual que la nave de Ulu Burum debía de llevar una parte de la carga reservada a objetos de uso suntuario, de la que se han conservado varios escarabeos y un cilindro sello.

Entre los materiales recuperados merece la pena señalar una lucerna de una mecha que aparece con claras señales de uso. Sin lugar a dudas nos está indicando que el mercante navegaba habitualmente tanto de día como de noche. Durante mucho tiempo la opinión casi unánime de los investigadores fue la de descartar por completo la navegación nocturna. Esta tesis llevo a buscar asentamientos fenicios separados por tramos regulares de costa que tendrían, entre otras finalidades, dar cobijo a los barcos para pernoctar (Gintas, 1948). Hoy sabemos que las travesías nocturnas eran tan habituales como las diurnas, al menos para los grandes mercantes que tienen serias dificultades para maniobrar en corto y sólo pueden atracar en puertos bien acondicionados. Por otro lado, la navegación de cabotaje. pese a ser un tópico muy extendido entre quienes no conocen directamente los problemas de la navegación, es más peligrosa que la de altura y sobre todo para los barcos de gran calado y poca maniobrabilidad. Precisamente, la falta de una infraestructura portuaria adecuada a grandes mercantes, y no la capacidad marinera de los barcos del segundo milenio a. C., debió de constituir, entre otras razones, la causa de que este tipo de barcos no hiciera su aparición en el Occidente Mediterráneo hasta bien entrado el primer milenio a. C. Este tipo de relación comercial requiere una situación colonial estable, con puertos seguros, no sólo desde el punto de vista náutico, sino también político, con garantías de que las empresas comerciales 
puedan tener seguridad económica y continuidad regular. Esta situación no se dará en Occidente hasta fines del s.IX a. C.. Las naves que debieron frecuentar las costas del Mediterráneo central y occidental durante el segundo milenio a. C., aquellas de debieron llevar la cerámica micénica a las costas de la península Ibérica, debían de ser más ligeras y polivalentes, aptas también para operaciones de exploración, razias, etc.. Son las que en líneas generales responden al modelo náutico que conocemos como hippos, del que nos ocuparemos más adelante.

Por último, señalar entre los hallazgos que nos ha proporcionado la nave de Gelidonya un importante lote de herramientas de carpintero de ribera o de barcos, los HRS $A N Y T$ de las fuentes ugaríticas, para las reparaciones que hubieran de efectuarse durante la travesía. Algunas de estas hachas han tenido una asombrosa continuidad a lo largo de la historia. las documentamos ya en el tercer milenio a. C. en las pinturas de la tumba de Nefer de la $V^{a}$ dinastía egipcia, abordo de naves cananeas, en navíos romanos y los actuales carpinteros de ribera siguen empleándola con un diseño básicamente idéntico al de la nave de Gelidonya. Indirectamente estos instrumentos nos confirman que entre la tripulación debía de haber algunos expertos carpinteros de barcos - HRS ANYT - para efectuar las reparaciones de emergencia, como sabemos cierto a través de una referencia tardía que nos proporciona Estrabón, y que dice así:

... "De aquí pasó a lberia, donde fletó un strongylos [equivalente al gaulos] y un pentekónteros: el uno para navegar por alta mar, y el otro para reconocer la costa. Embarcó en ellos instrumentos agrícolas, semillas y carpinteros de ribera, con el propósito de que si la navegación se prolongaba, pudiese invernar en la isla"... (Estrabón, II, 3,4).

Seguramente la nave de Gelidonya también iba preparada para un largo periplo comercial y tal vez con estancias prolongadas en distintos lugares como nos indican los restos de recipientes de cestería con espigas de cereal en su interior, lo que también coincide perfectamente con la información que nos proporciona Estrabón al relatarnos el periplo que preparaba Eúdo- 
xos de Kyzikos y en la que por añadidura volvemos a corroborar que la mejor y más segura navegación para los gauloi era la de altura.

El pecio de Ulu Burum (figura 4) nos ha permitido por primera vez disponer de documentación arqueológica directa a partir de un barco cananeo contemporáneo de los de Kenamon para estudiar la arquitectura naval. El yacimiento de Llu Burum, situado en la costa de Kas (Turquía), está siendo excavado desde 1984 por el equipo de G. Bass del Institute Of Nautical Archaeology de Texas (Bass, 1986; 1987; Bass / Frey / Pulak, 1984; Pulak, 1988). Las sucesivas campañas de excavación han puesto al descubierto un navío mercante datado en el siglo XIV a. C...

Entre las estructuras del barco puestas al descubierto destacan una sólida quilla, relativamente bien conservada y las tracas ensambladas que parten de ella para configurar el pantoque de la nave. A la espera de los resultados definitivos, todo parece indicar que estamos ante un gran navio mercante, con cubierta sostenida por baos y una bodega destinada a la carga comercial. Dos mamparos dividían la bodega en tres secciones longitudinales; la más amplia corresponde a la parte central de la bodega. Este espacio albergaba el cargamento principal, mientras que los espacios más reducidos, situados respectivamente en las carenas de la aleta y de la amura, guardaban objetos lujosos, suntuarios, de gran valor y volumen reducido. Al menos siete grandes anclas de piedra viajaban en la cubierta del navío.

Habremos de esperar aún algunos años hasta tener los estudios completos de la arquitectura naval. No menos importante, aunque no es el asunto central de este trabajo, es el cargamento principal que estaba básicamente compuesto por: 1. Una importante partida de lingotes de cobre en forma de "piel de toro", junto a utros menores de format sircular: 2. Un cargamento de ánforas cananeas con contenidos varios. 3. Cuatro grandes pithoi de cerámica que envasaban una mercancía no determinada hasta ahora. 4 . El cargamento principal se completaba con una serie de objetos valiosos, típicos de los intercambios de bienes de prestigio, tan habituales en las relaciones internacionales de la época. De los que vale la pena señalar: A. Un lote de cerámica fina chipriota. B. Un lote de cerámica fina micénica. C. Espadas de bronce cón empuñadura de marfil, junto con puntas de 
lanza, escoplos, etc., también de bronce. D. Diversos objetos de oro, entre ellos un cáliz seguramente micénico, amuletos y colgantes diversos cananeos, uno de ellos con la diosa Astarté en relieve. E. Torques o brazaletes de plata. F. Resina de ámbar. G. Vidrio y marfil en bruto, además de escarabeos egipcios, algunos con el cartucho del faraón Amenhotep III y un cilindro-sello casita.

Los análisis de los restos orgánicos (Haldane, 1993) de la nave de Ulu Burum han revelado que una parte muy importante de la carga comercial estaba constituida por productos perecederos, que sólo un escrupuloso estudio ha podido identificar. Una de estas mercancías, en forma de materia prima para la fabricación posterior de ungüentos perfumados, era la resina de terebinto (trementina blanca muy olorosa) envasada en algunas ánforas cananeas. También algunos stirrup jar micénicos eran contenedores de resinas. Más de un millón de semillas de granada se han recuperado de los sedimentos de distintas jarras y pithois. Otras ánforas cananeas contenían aceitunas, una sola proporcionó 2.500 huesos de este fruto. Almendras, bellotas, piñones, pistachos silvestres, higos, semillas de dos tipos distintos de uvas, así como cilantro, comino negro, semillas de zumaque, cebada, trigo y tres tipos distintos de garbanzos, completan un panorama muy complejo de mercancías difíciles de documentar en los registros arqueológicos habituales. Conviene recordar que muchas de las semillas y plantas aquí reseñadas tienen importantes utilidades médicas, asunto, por otro lado escasamente atendido por la investigación prehistórica.

Es evidente que nos encontramos ante un mercante que formaría parte de una flota que ejercía un importante papel redistribuidor de productos propios y ajenos, procedentes de ámbitos geográficos muy distantes, además de comercializar mercancías propias, romo el vino cananen.

Este tipo de mercantes seguramente seguían la ruta habitual que partiendo de Biblos y / o Ugarit, tocaría puertos chipriotas como Enkomi. Ascendiendo hacia el Norte navegaría por la costa de Turquía, donde se encuentra Mersin, que a la sazón era un importante centro costero de la región de Arzawa, controlada por los hititas. En la costa de esta región se produjo el naufragio. Otros mercantes con mejor suerte debieron comple- 
tar el periplo comercial que en dirección al Oeste unía Rodas y Greta, para acabar en dirección Sur en Mersa-Matruh en la costa africana. Desde aquí se alcanzaba en navegación de cabotaje el delta del Nilo y los puertos cananeos de Ascalon, Akko, Tiro, Biblos y Ugarit, que cerraba así el circuito comercial documentado en la nave de Ulu Burum.

Otras mercancías transportadas por esta nave, como el ámbar o el marfil, tienen un origen exterior al circuito señalado. Debemos de suponer que otros grandes centros comerciales redistribuían objetos procedentes del comercio lejano, en los que las redes de intercambios indígenas debieron jugar un papel crucial. Sin duda Creta y las ciudades micénicas ejercieron este papel de intermediarios entre las mercancías procedentes de rutas indígenas occidentales y el comercio de productos regionales del Mediterráneo Oriental, como el vino cananeo, o el cobre de Chipre, los cedros del Líbano, la púrpura fenicia, etc. Tanto el comercio con el Mar Negro como las rutas del Adriático y del Tirreno estaban perfectamente controladas por los barcos micénicos contemporáneos del Ulu Burun. Una de las rutas por las que llegaba el ámbar que transportaba la nave de Ulu Burum al Mediterráneo bajaba precisamente por el Adriático, al igual que el estaño del golfo de León lo hacía por la costa tirrénica. Un lingote de estaño hallado en la costa cananea de Haifa (s. XVI-XII a. C.) lleva precisamente una marca de control minóico-chipriota (Tore / Zemer, 1987), mientras que otros de tipo egeo, idénticos a los que cargaba el barco cananeo de Gelidonya (Bass, 1976), hallados en Cerdeña (Lilliu, 11987:119), también con marcas inscritas, constituyen un claro argumento para sostener la existencia de estos contactos regulares entre el mar sardo-tirrénico y la costa del Líbano al menos desde la segunda initad del II milenio a. C., en los que la marina regional nurágica debió de jugar un importante papel.

El marfil en bruto que cargaba la nave de Ulu Burum pudo haber llegado hasta el delta del Nilo en barcos fluviales nubios, tal vez en embarcaciones de papiro como las que nos muestran muchas fuentes iconográficas egipcias (Resch, 1967), pasando por Tebas, Tell-el-Amarna, donde las ánforas cananeas como las que viajaban en la nave de Ulu Burum están bien documentadas (Grace, 1956), hasta los puertos del delta, donde los 
barcos cananeos se harían cargo de colocarlos en los circuitos de redistribución ultramarina.

El estudio de los mercantes fenicios del primer milenio a. C. choca irremisiblemente con la escasez de documentación tanto literaria como iconográfica. Menos aún puede ofrecernos la documentación arqueológica, pues ningún yacimiento correspondiente a esta época ha podido ser estudiado.

La denominada "crisis del $1200 "$ puso fin a la próspera marina cananea de Ugarit. Los ataques de los pueblos del mar a las ciudades costeras del Levante son sin duda una de las causas de este cese traumático de los periplos comerciales que antes habíamos visto. Durante el periodo Ugarítico Reciente (1365-1200 a. C.) se detectan destrucciones masivas y violentas de ciudades seguidas de incendios (Poyato / Vázquez Hoys, 1989:589-595), como ocurre por ejemplo en el yacimiento Ras Ibn Hani, muy próximo a Ugarit.

Pasado este periodo crítico, Tiro y Sidón retomarán el protagonismo que hasta entonces había tenido Ugarit. La expansión colonial ultramarina se iniciará con la fundación de Kitión a principios del milenio y poco tiempo después los viajes al Extremo Occidente serán ya una realidad con confirmación arqueológica. Sin embargo, de esta intensísima etapa de fundaciones coloniales apenas nos ha quedado registro iconográfico naval. Toda la documentación relevante se concentra en las terracotas chipriotas y en algunas pinturas esquemáticas sobre vasijas cerámicas del periodo Chipriota Arcaico I (700-600 a. C.).

A nuestro juicio, aunque tanto las terracotas como las cerámicas son de fabricación local, no dudamos que intentan representar los mercantes fenicios que a la sazón operaban en la isla de Chipre. No en balde la presencia fenicia en la isla marcará un antes y un después en la historia náutica chipriota, así las representaciones náuticas del segundo milenio nada tienen que ver con las que vemos a partir de la fundación de kitión. 
Una magnífica representación de un gaulos fenicio la tenemos en la terracota procedente de Amathus (Metropolitan Museum of Art, New York, $\mathrm{n}^{\circ}$ 74-51-1752) que ha sido ya estudiada en varias ocasiones (Landström, 1969; Goettlicher, 1978; Westerberg, 1983; Corretti, 1988). Se trata (figura 5) de un mercante con una bodega de gran puntal. La quilla aparece muy bien marcada y termina en la proa formando un tajamar. Este elemento, que no se había podido documentar con anterioridad, debió de representar una mejora notable en la navegabilidad de estos buques. La terracota ha sido datada hacia el 600 a. C., lo que a su vez se convierte en una referencia cronológica para la introducción del tajamar en los grandes mercantes, seguramente una incorporación fenicia a los gaulos de un elemento propio de embarcaciones muy ligeras y que en ellas es en realidad la prolongación de la quilla, a veces monóxila, en la unión con la roda.

Un codaste muy elevado va provisto de una balconada que sobresale por la popa. Aparece muy bien marcada la falca o escalamote que realza la borda del navío. lo que corrobora nuestra opinión contraria a la de Landströn en la interpretación de este elemento ya comentada a raíz de las naves de Kenamon. Por primera vez encontramos también documentadas las cintas, o largos tablones que de popa a proa reforzaban el casco por el exterior y poco más arriba de la línea de flotación del navío. Seguramente es también otra innovación fenicia que luego incorporarán otras marinas como la griega.

Una segunda terracota (figura 6), también procedente de Amathus (Bonino, 1965; Westerberg, 1983:102), nos representa de nuevo un mercante, que, sin embargo, tiene elementos estructurales únicos que no se han podido documentar jamás. La terracota reproduce un gaulos con bodega de alto puntal. Aunque no tiene cubierta, pensamos que es una licencia del artista para dejarnos ver su interior. De otra forma no tendría sentido la línea de imbornales que aparecen en el trancanil, lo que necesariamente implica la existencia de cubierta en el modelo real. En la parte central del casco se encuentra muy bien realizada la carlinga, con la cavidad para recibir el mástil, que seguramente era de madera y se ha perdido. A diferencia de otras representaciones de mercantes fenicios no tiene escalamote 
y, por el contrario, la borda es muy alta a juzgar por la distancia vertical tan notable que existe entre la regala y los imbornales.

Bonino (1965) interpretó las traviesas que aparecen en el interior del casco de babor a estribor como los baos y los puntos de pintura negra sobre ellos con las señales donde irían firmes los obenques. Por nuestra parte pensamos que esta interpretación es errónea. El sitio donde siempre se afirman los obenques es en la regala o en groeras insertas a la altura del trancanil y / o de las cintas, pero nunca en medio de los baos. En todo caso podrían indicar el lugar de los motones con roldanas para gobernar las brazas y escotas. Aunque no creemos que el artista llegase a estos extremos y más bien debemos considerar los trazos pintados como motivos simplemente estéticos.

La bodega está dividida en dos partes claramente diferenciadas, aunque desiguales en su capacidad. Dos tercios largos de proa estaban destinados a la carga comercial del buque, mientras que algo menos de un tercio en popa, bajo el puente, lo ocupaba un camarote cerrado al que se accede mediante un portal con dintel arqueado.

Sobre el camarote de popa se sitúa el puente de gobierno, que constituye

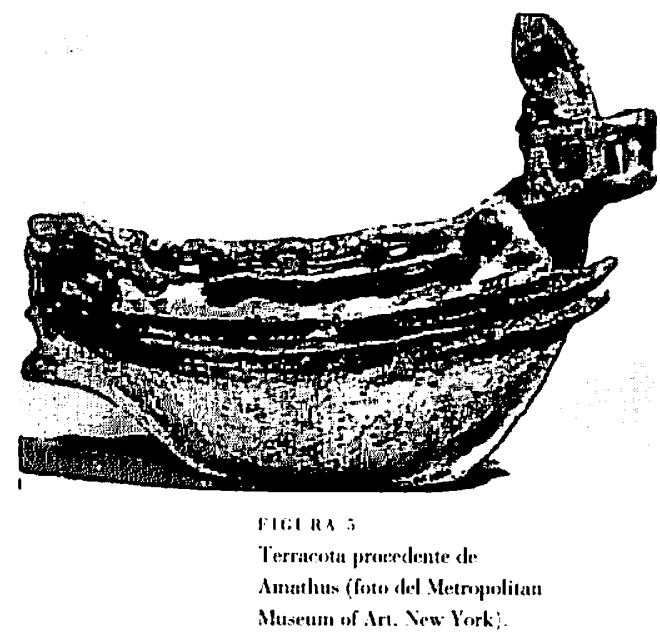

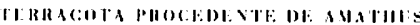

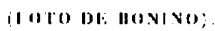

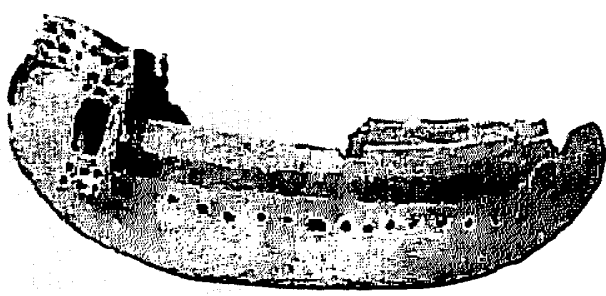

ricil ith ind

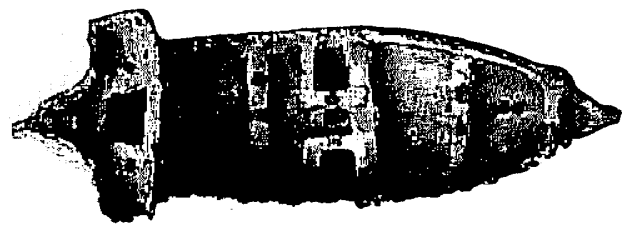

FIC:I RA BI

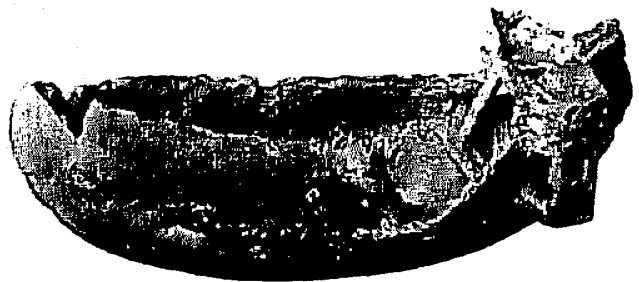

FIOElas oc: 


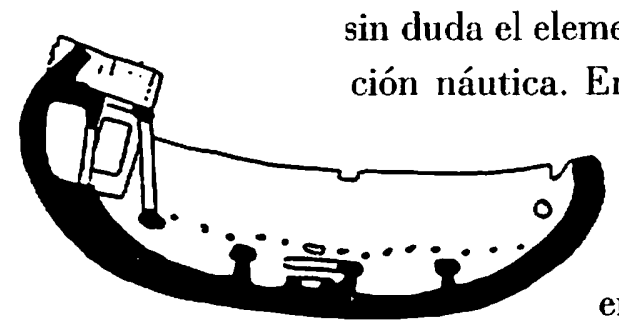

sin duda el elemento más original (figura 7) de esta representaFIC:URA ?A parten dos armazones exteriores y sobrepuestos en las aletas de babor y estribor que llegan hasta la línea de flota-

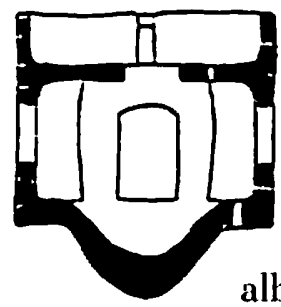
ción, marcada aproximadamente por los imbornales. En el suelo de estas estos armazones, que en vista vertical constituyen dos balconadas de planta cuadrada que prolongan el puente por las aletas, se practicaron sendas gateras para pasar los gobernáculas. Estos armazones o estructuras para Fic.1 th. : : en nada conocido hasta ahora. La iconografía náutica fenicio chipriota sobre cerámica (Kara-
georghis / Gagniers, 1974; Westerberg; 1983) nos ha

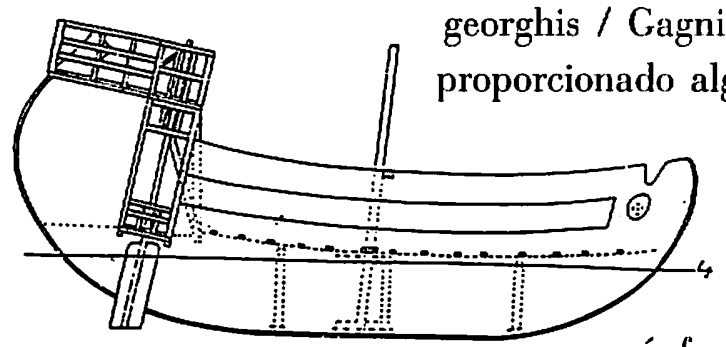
La iconografía náutica fenicio chipriota sobre cerámica (Kara-
georghis / Gagniers, 1974; Westerberg; 1983) nos ha central por la que se desciende a la bodega. La estructura está sostenida en su parte delantera por dos puntales que se apoyan en un bao. Del puente, y conectados con él,

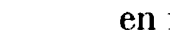

albergar los timones son realmente únicos y no tienen parangón tismo no tienen mucho que añadir a las de bulto redondo que hemos estudiado. Una, que con toda seguridad representa un gaulos cargado de

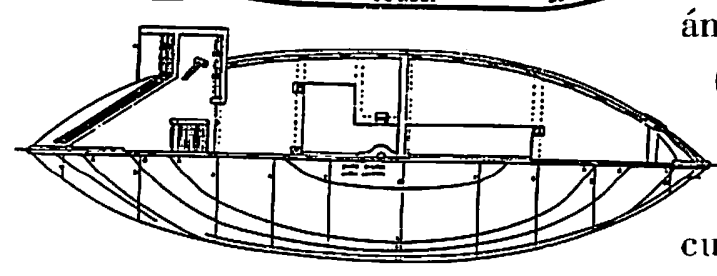

ánforas (figura 8), aparece sobre un oinocoe (British Museum n" Inv. 1926, 6-28.9). El casco, como puede comprobarse a partir de la pintura original, no es tan curvado como lo interpreta Westerberg Higrin $7:$ (1983:116). Tiene una roda prácticamente vertical, con un tambucho, casetón o estrado en la proa sobre el que un marinero se dispone a fondear un ancla de piedra (McCaslin, 1980:58). E1 codaste es extraordinariamente desarrollado y curvado al interior. Se gobierna mediante dos timones de espadilla en las aletas. La nave va aparejada con un mástil con cofa y una verga sobre la que aparece recogida 
una vela. La jarcia aparece representada de forma sumamente esquemática, con un doble trazo en forma de cruz N11:1 IIA * Pintura chipriola solure orrímica (segúm Wintorberg. con el caswo, que se corta en el mástil, lo que no permite deducir cuáles son en realidad sus funciones. Tres personajes componen la tripulación: un timonel, el marinero ya mencionado que está anclando el navío y un tercer marinero que defeca subido en uno de los gobernáculas.

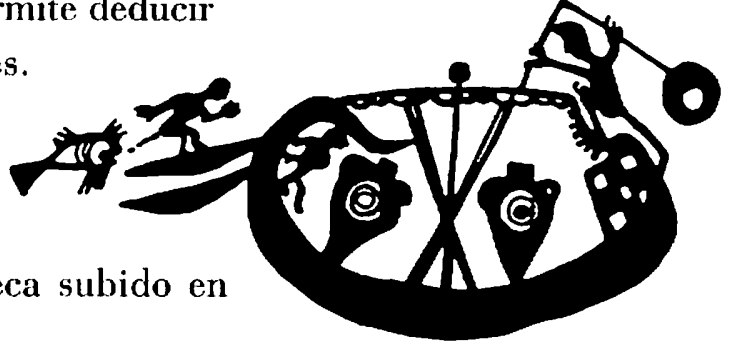

A partir de un grabado (figura 9) procedente del puerto de Utica, al parecer datado en el s. III a. C. (Landströn, 1983:35) tenemos la imagen de un gaulos cartaginés provisto de un gran tajamar que incorpora un elemento entre los aparejos muy poco frecuente, salvo en navíos romano imperiales. Se trata de un mástil suplementario fuertemente inclinado hacia la proa y provisto de una vela cuadra cazada con dos escotas. Aunque su ubicación sobre el eje de crujía es notoriamente retrasada, la inclinación nos permite suponer que ejercía las veces de un artimón o más bien de un bauprés. Navíos antiguos con palos Pinu ura del puerto de Licion trinquete y mayor están documentados, aunque de forma muy rara, tanto sobre embarcaciones de guerra (Casson, 1980), como en navíos mercantes, tal y como lo vemos en el barco pintado en una tumba de Tarquinia (Moretti, 1961; Casson, 1963).

EL HPPOS A TRAVÉS DI: LAS FUENTES IITERARIAS Y ARQUEOLOGIGAS

Las fuentes identifican los hippoi con los barcos fenicios que tenían un akroteria en forma de cabeza de caballo (figuras 10-11). En la Antigüedad la nacionalidad de los navíos se identificaba por determinadas figuras, en 


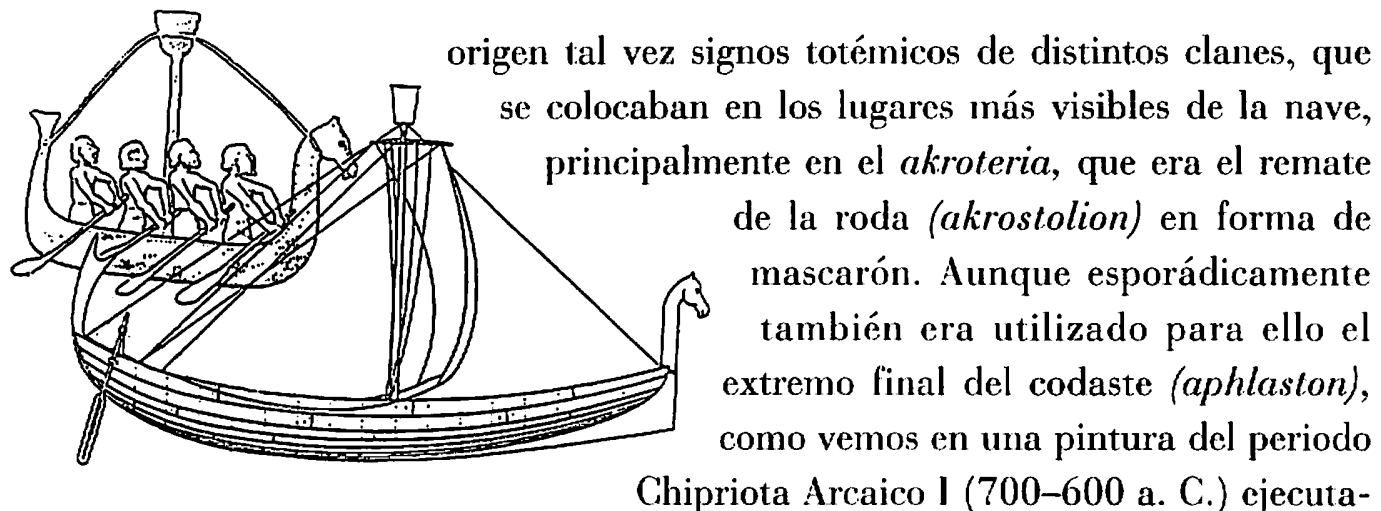

FIC:RA II)

Reconstrucción d: un hippos a partir de los relieves ilo Korsabad (scguin I anditrïm!. da sobre un oinocoe (Museo de Chipre en Nicosia, $n^{\circ}$ inv. 194? /1-16 / 1) en la que aparece una nave ligera con el aphlaston acabado en un mascarón con forma de oca. Pocos textos son tan clarificadores para esta cuesión como el siguiente:

... "exploró por dos veces [Eudoxos de Kyzicos] las costas del Océano Indico: a la vuelta de su segundo viaje, tocó en las costa etiópicas ... Se encontró también con la proa de madera de un navío, en el que estaba tallada la figura de un caballo, y supo que eran los restos de un naufragio de cierta escuadra que partió de Occidente; con ella emprendio de nuevo su viaje de regreso ...Llevó su proa al puerto comercial [de Alexádreia] y allí supo que era de los gadeirítai, y que éstos, además de los grandes navíos que armaban los comerciantes, usaban otros más pequeños, propios de las gentes pobres, a los que llamaban hippoi, por el mascarón de sus proas; con ellos pescaban a lo largo de las costas de Maurousía, hasta el río Líxos"... (Estrabón, II, 3,4).

Fis: ins 11

Itppoi de los relieves de bronce de la puerta de: Bninumi.

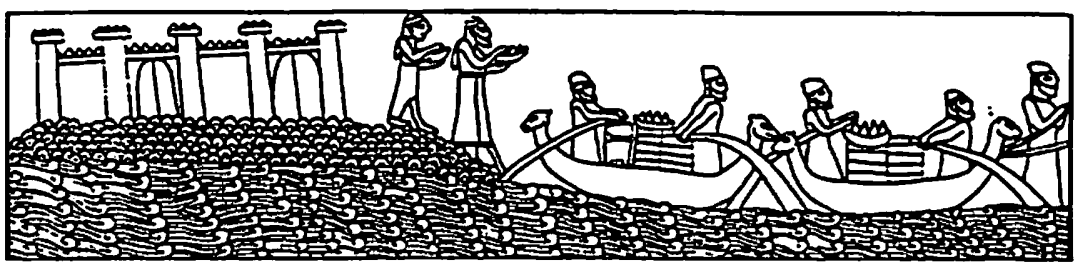


Sin embargo, con ser todo ello cierto, aquí nos interesa sobre todo un determinado tipo de nave, que en origen se identificó por los akroterias en forma de hippos por ser seguramente un invento fenicio. Durante el segundo milenio a. C. este modelo náutico era también usado por los aqueos; y así lo vemos representado en muchos vasos micénicos (Marinatos, 1933; Laviosa, 1972), aunque la mejor imagen (figura 12) de este tipo de navío la tenemos en una "jarra de estribo" del Heládido Reciente IIIC: (s. XII a. C.) hallada en Esciros (Melena, 1991). Otro navío pintado también en un vaso del Heládico Reciente IIIC, hallado en Asine (Casson, 1971, figs:28-29), tal vez representa (figura 13 ) un mercante micénico polivalente similar al de Esciros. Interesa destacar que el barco de Asine parece ir provisto de tajamar, del que carece la nave de Esciros pese a la obsoluta contemporaneidad de ambas representaciones. Durante el segundo milenio a. C., y aún antes, existen abundantes representaciones de embarcaciones ligeras con tajamar, sin embargo, $y$ aunque representaba una notable mejora técnica, esta claro que no todas las embarcaciones la adoptaron. Los trazos, en número de diez u once que sobresalen del casco por la quilla podrían estar Burco micénico ligero de Asisse (sorgin Cassonj). indicándonos el numero de remeros por banda, no obstante el barco fue representado con la vela cuadra izada, provista de relingas y refuerzos, seguramente de cuero, formando un reticulado.

Conviene advertir que los akroteria con imagen de hippoi pueden rastrearse desde el Heládico Primitivo s. XVIII a. C., como en la terracota de Orchómenos (Buchholtz, H. G. / Karageorghis, 1973:99), aunque ésta también podría identificarse con un ánade, y en distintos sellos minóicos (Marinatos, 1933). Sin embargo aparecen sobre navíos que no responden al tipo náutico que aquí pretendemos analizar. 
La parquedad de fuentes iconográficas y literarias fenicias podemos compensarla en parte con los relatos náuticos de la Odisea, que a nuestro juicio (Guerrero, 1994), se realizan mayoritariamente en naves de estas características y no en las triacónteras y otras naves guerreras que vemos en las cerámicas del Geométrico (Kirk, 1949; Casson, 1991), en las cuales difícilmente se hubiesen podido desarrollar muchos de los episodios que en dicha obra épica se nos relatan. En la Odisea se hace frecuente mención a las cóncavas naves (Od., XII, 228-230) y ésta no es precisamente la forma de las naves triacónteras o pentecónteras que vemos en las representaciones del Geométrico, más bien éstas son navíos de quilla monóxila, de muy escasa manga y poco puntal. La mejor representación de las cóncavas naves de la Odisea la tendríamos en la nave de Esciros, ya citada.

La versatilidad y capacidad marinera de los hippoi puede deducirse de su empleo en las navegaciones que los gaditanos llevaban a cabo por la costa africana, hasta el sur de Agadir, por lo menos, como hemos visto en el texto de Estrabón.

Fijemos primero las características náuticas del hippos independientemente de su akroteria. Un cálculo exacto es difícil, pero teniendo en cuenta todos los datos disponible pensamos que podemos estar frente a una nave de unos ocho a doce metros de eslora, sin bodega cubierta de carga, aunque con sentina. La propulsión era siempre mixta, mediante vela cuadra y remeros en número harto discutible, aunque debía de depender mucho del tipo de empresa marinera. Así, en las aventuras se relatan razias y otras acciones armadas lo más frecuente es que oscilen entre los veinte y los treinta remeros, que ostentan entre ellos similar rango social, aunque los conduce siempre uno de los mas experimentados (Guerrero, 1994: 113-141). Valgan como ejemplos ilustrativos los siguientes pasajes:

... "De común acuerdo encargaron a Tifis de dirigir la caña del timón de la nave de buena quilla"... (Argonautiká., I, 400). 
... "Los mancebos que le acompañaban son los que más sobresalen en el pueblo, entre nosotros, y como capitán vi embarcarse a Méntor o a un dios que en todo le era semejante"... (Od., IV, 675-683).

Los marineros, y a la vez remeros, van sentados sobre bancadas al descubierto, aprovechando los espacios vacíos para cargar mercancías de escaso peso y volumen, aunque de gran valor como objetos de prestigio, entre los que debemos contar el vino, las vasijas de metales preciosos. armas, púrpura, etc.

... "Tomó del carro los hermosos presentes - los vestidos y el oro-y los dejó en la popa del barco" ... (Od., XV, 221-228).

... "El rojo licor [dulce vino] aún no faltaba en las naves, pues habiamos hecho gran provisión de ánforas al tomar la sagrada ciudad de los cicones”... (Od., IX, 151-171).

... "Hízome Marón ricos dones, pues me regaló siete talentos de oro bien labrado, una crátera de plata y doce ánforas de un vino dulce y puro, bebida de dioses"... (Od., IX, 194-213).

Los remos trabajarían fijos en toletes o chumaceras sobre la regala, y nunca a través de gateras como ocurre en las birremes y trirremes. Naturalmente en la propulsión debía alternarse la vela cuadra cuando los vientos largos de empopada hacían innecesaria la boga: cuando no, se arriaba la vela, e incluso el mástil y la verga, se colocaban los remos en los toletes y se continuaba la travesía, igualmente eran necesarios los remos para remontar los estuarios de los ríos y llegar a tierras del interior.

... “Las naves iban de través, cabeceando; el impetuoso viento rasgó las velas en tres o cuatro pedazos. Entonces las amainamos, pues temíamos nuestra perdición: y apresuradamente, a fuerza de remos, llevamos aquellas a tierra firme”... (Od., IX, 63-83). 
... "Plegaron y recogieron el velamen en el cóncavo arcón para las velas. Luego retiraron inclinadamente el propio mástil, y velozmente arribaron remando a la amplia desembocadura del río"... (Argonáutika, II,1264).

El gobierno de estos navío parece que siempre se realizaba con un sólo timón de espadilla en la aleta de estribor, y no dos como en el gaulos. Resulta ocioso recordar que el gobernácula no es necesario cuando se navega bogando, como claramente nos muestran los bajorrelieves de Korsabad, por lo que debía de disponer de un fácil sistema de montaje. Las pocas representaciones iconográficas de hippoi, incluidas las de los barcos micénicos equivalentes, así parecen confirmarlo. Las fuentes literarias también se refieren al timón siempre en singular. Así, por ejemplo:

... Arrojolo detrás de nuestro bajel de azulada proa, y poco faltó para que diese en la extremidad del gobernalle”... (Od., IX, 562-566).

... "Y a ti, piloto, voy a darte una orden que fijarás en tu memoria, puesto que gobiernas el timón de la cóncava nave"... (Od., 228-2230).

Los aparejos: mástil, vergas y velas, son siempre en este tipo de barcos abatibles y desmontables. Tanto la iconografía, que luego veremos en los relieves de Korsabad, como las fuentes literarias no dejan lugar a dudas. Las referencias directas e indirectas a este asunto en la Odisea y en la Argonautiká son muy numerosas, por ejemplo:

... "Echáronla [la negra embarcación] al mar profundo, pusieron el mástil y el velamen"...(Od., VIII, 49-63).

... "Lanzando la nave al vasto ponto después de izar el mástil y de descoger las blancas velas"... (Od., XII, 420-425).

... ' Levantáronse todos, fuéronse a la ribera del mar, sacaron en el acto la negra nave a tierra firme y los diligentes servidores se llevaron los 
aparejos. Seguidamente se encaminaron juntos al ágora... (Od., XVI, 368-373).

... "Primeramente saquemos la nave a tierra firme y llevemos a las grutas nuestras riquezas y los aparejos todos"... (Od., X, 443-447).

... "Enderezaron el mástil sobre la crujía y lo sujetaron con cables, tensándolo por ambos lados. Después desplegaron la vela, sujetándola al palo, y la hinchó un viento ligero. Anudando sobre la cubierta los cables fíjamente sobre sus pulidas amarras"... (Arg., I, 550-600).

Estas y otras referencias que a continuación analizaremos nos introduce en el estudio de la jarcia de estos navíos. Por lo que respecta a la jarcia mayor es indispensable para mantener el palo firme la existencia de burdas y estays, a ello se refiere sin duda la cita anterior, y puede ser también útil la siguiente:

... "Un torbellino rompió los dos cables del mástil, que se vino hacia atrás"... (Od., XII, 426-430).

La iconografía no es muy explícita para el estudio de la jarcia de labor. En los relieves de Korsabad sólo tenemos representado el estay y la burda. Sin duda serían necesarios los brioles para izar y arriar velas, que es una acción que se repite continuamente en todos los relatos marineros, dando por seguro que este modelo náutico había suprimido ya la verga inferior. A los brioles se refiere la siguiente referencia literaria:

... "Telémaco les mando que aparejasen la jarcia ... Izaron el mástil de abeto, lo metieron en el travesaño [carlinga], lo ataron con sogas, y acto continuo extendieron la blanca vela con correas bien torcidas"... (Od., $312-324)$.

Las brazas, firmes en los penoles de la verga eran indispensables para el manejo de las velas. EI único documento iconográfico que las reproduce 
en este tipo de navíos es en la pintura de la tumba cartaginesa norteafricana de Kef el-Blida. De forma combinada actúan con las brazas las escotas firmes en los puños bajos de las velas, sin embargo no tenemos documentación de ello. De su existencia no podemos dudar, si no sería imposible cazar las velas cuando flamean. Una magnifica y completa representación de la jarcia de labor de un navío ligero, aunque no se trata exactamente de un hippos, la tenemos en la copa ática de figuras negras (540-530 a. C.) de Vulci, del pintor Exékias, que representa a Dionisos sobre la cubierta de un navío (Munich, Staatliche Antikensammlungen, $\mathrm{n}^{\mathbf{0}}$ 2044).

Seguramente la jarcia tanto mayor como de labor eran gúmeas, es decir cabos de esparto o papiro. Sin embargo otra cordelería destinada a las relingas, a las ligaduras y sujeciones de diversas piezas podían ser de otros materiales, especialmente cuero, como ya hemos visto para el caso de los brioles. Veamos algunos ejemplos:

... “Como hallara debajo del pórtico el cable de papiro de una corva embarcación, las ató con él"... (Od., XXI, 410-415).

... "Sobre el mástil hallábase una soga hecha de cuero de buey"... (Od., XII, 443-448).

..." la cuerda formada por retorcido intestino de una oveja"..." (Od, XXI, 428-440).

Los remos debían fijarse a los toletes y chumaceras con correas hechas de cuero. Son varias las veces que la Odisea nos advierte de este detalle:

... "Pusieron el mástil y las velas, luego aparejaron los remos con correas de cuero, haciéndolo como era debido"... (Od., IV, 818-827).

... 'La negra embarcación, echáronla al mar profundo, pusieron el mástil y el velamen, y ataron los remos con correas"... (Od., VIII, 49-63). 
Los materiales de construcción de un navío son sin duda muy diversos y de variados orígenes. Para los barcos fenicios contamos con una corta información literaria que nos proporciona Ezequiel (XXVII, 3-9):

\begin{abstract}
... "Tiro tú te decías: yo soy [un navio] de perfecta hermosura. En el corazón de los mares están tus confines; los que te edificaron te hicieron perfectamente hermosa; de cipreses de Sanir hicieron tus quillas, de cedros del Líbano tus mástiles; tus remos, de encinas de Basán; tus bancos, de boj incrustado de marfil, traído de las islas de Kittim. De lino recamado de Egipto, eran tus velas para servir de enseña; de jacinto y púrpura de las islas de Elisa tus toldos. Los habitantes de Sidón y de Arvad eran tus remeros, y los más expertos entre ti, joh! Tiro, tus pilotos. Ancianos de Guebal, con sus más hábiles obreros. calafateaban tus junturas...".
\end{abstract}

Los materiales pueden ser usados naturalmente en cualquier tipo de barco, y la intención poética de Ezequiel seguramente idealiza algunos detalles como el marfil incrustado, que parece un lujo excesivo en un barco destinado a la navegación ordinaria, aunque tiene algunos aspectos muy aprovechables y coincidentes con los que sabemos a través de la Odisea, como es la cuidadosa selección de maderas para las diferentes partes y aparejos del barco. Del relato de Ezequiel parece desprenderse que, no sólo los akroterias podían servir de elemento identificador, sino también las velas, que seguramente pintadas con insignias podían tener la misma función. No podemos saber a ciencia cierta a qué tipo de navío se refiere Ezequiel, aunque la referencia a propulsión de velas y la instalación fija de bancos para los remeros, nos inclina a pensar que estamos ante un hippo o navío muy similar y no un gaulos.

Muchas de las referencias de la Odisea sobre los aparejos y materiales de construcción, ya citadas, seguramente son válidas también en el caso de los hippoi. Para el mástil se usa casi siempre el abeto (Od., XV, 312-325). mientras que para los remos las referencias más frecuentes son a las maderas de álamo negro (Arg., I, 1188) y también al abeto (Od., XII. 
173-194). No obstante, la referencia más completa sobre las maderas y sistemas de construcción lo encontramos en el relato que describe la construcción de la balsa de Odiseo. Como puede apreciarse, es un verdadero navío y no una simple balsa. Está claro que Odiseo, ayudado por Calipso, termina la nave construyendo una cubierta que coloca sobre los baos ("espesas vigas"), lo que implica necesariamente una bodega de carga de "ancho y redondeado fondo". La referencia es tan explícita y rica en detalles que es preferible darla completa, desde los trabajos previos de buscar las distintas clases de madera hasta la instalación de los aparejos, arboladura y velamen:

‘... y le llevó a un extremo de la isla, donde habían crecido altos árboles -chopos, álamos y el abeto que sube hasta el cielo-, todos los cuales estaban secos desde antiguo y eran muy duros y a propósito para mantenerse a flote sobre las aguas... él se puso a cortar troncos y no tardó en poner fin a su trabajo. Derribó veinte, que desbastó con el bronce, pulió con habilidad y enderezó por medio de un nivel, Calipso, la divina entre las diosas, trájole unos barrotes con los cuales taladró el héroe todas las piezas que unió luego, sujetándolas con clavos y clavijas. Cuan ancho es el redondeado fondo de un buen navío de carga... Labró después la cubierta, adpatándola a espesas vigas y dándole remate con un piso de largos tablones; puso en el centro un mástil con su correspondiente antena, y fabricó un timón para regir la balsa... La lastró con abundante madera. Mientras tanto Calipso, la divina entre las diosas, trájole lienzo para las velas; y Odiseo las construyó con gran habilidad. Y, atando en la balsa cuerdas, maromas y bolinas echóla por medio de unos parales al mar divino..." (Od., V, 229-261).

Es probable, a pesar de la referencia a clavos y clavijas de la cita anterior, que algunos de estos navíos fueran cosidos, o que emplearan sistemas mixtos como se ha comprobado arqueológicamente en las naves de Mazarrón (Negueruela, 1996). No hay referencias muy explícitas en Homero al asunto, salvo una indicación en la Iliada al estado de conservación de las naves: 
... "Nueve años del gran Jove transcurrieron ya; los maderos de las naves se han podrido y las cuerdas están deshechas... (Il., II, 135).

Una evidencia arqueológica directa de excepcional importancia la tenemos en los navíos fenicios de Mazarrón (Negueruela, 1996), a los que ya hemos hecho referencia. Seguramente se trata de dos naves del tipo hippos ya que tienen una eslora aproximada de unos ocho metros. El segundo de estos barcos, cuyo casco se encuentra en un excepcional estado de conservación, pues conserva hasta la tapa de la regala, va completamente cargado hasta la borda con ánforas fenicias gaditanas y galena. Aún permanece sin excavar, sin embargo, la documentación que nos puede proporcionar este yacimiento para el estudio de este tipo de navíos es sencillamente única y probablemente irrepetible. De momento parece confirmarnos la extraordinaria capacidad marinera de estos pequeños mercantes, que reunidos en flotillas se aventuraban desde el Occidente del Estrecho hasta, por lo menos, las Baleares, dada la exacta coincidencia entre el cargamento de estas naves y los materiales de Sa caleta de Ibiza (Ramón, 1991). Seguramente podremos documentar que la carga iba al descubierto, es decir sin tablazón de cubierta y que las bancadas, como ya hemos apuntado, se ponían o quitaban dependiendo de la misión: pesca, trasporte, razia, etc.. Las cuadernas de los barcos de Mazarrón presentan la novedad de ser de sección redonda. El sistema combinado de pasadores y clavijas con el cosido es otra de las novedades extraordinarias de este yacimiento. También se ha podido comprobar la existencia de calafateado, aunque esto era ya algo conocido por las fuentes y la arqueología. En una tablilla de Pilos (An 615) se hace referencia a unos $M A-R A-T E-W E$, que se han interpretado como artesanos calafateadores (Ruipérez / Melena, 1990:137); también Ezequiel (XXVII, 3,9), refirinedose seguramente a un hippo nos dice que ... "Ancianos de Gebal, con sus más hábiles obreros, calafateaban tus junturas"... La quilla del Mazarrón 1 dispone de una extraña forma de ensamblaje con otra pieza no documentada hasta ahora, que tal vez pueda ser un tajamar.

El sistema de fondeo eran las anclas de piedra. Hasta el siglo VI a. C. no se documenta con claridad el ancla de metal (Gianfronta / Pomey, 
1981), aunque las de piedra debieron perdurar aún mucho tiempo. Están relativamente bien conocidas a partir de los hallazgos arqueológicos (Frost, 1963; Tusa, 1972) y de la iconografía, como en los oinocoes con temas náuticos del periodo Chipriota Arcaico I (Westerberg, 1983). En el Bajo de la Campana (Cartagena), donde se hundió un barco fenicio contemporáneo de los de Mazarrón tenemos precisamente un ancla de piedra que tal vez pudo corresponder a este barco (Roldán / Martín / Pérez, 1995), es de forma triangular con un agujero en su vértice superior que hace las veces de arganeo. Este tipo de anclas debía de garrear bastante en fondos arenosos, algo menos en algas, y su comportamiento debía de ser mucho mejor en fondos rocosos. Precisamente para hacerlas más eficaces podían ir provistas de uñas. También la información literaria tiene buenas muestras del uso de anclas de piedra, como por ejemplo:

... "Aquí fondeó Argo ... Desembarcaron también la pequeña piedra de anclaje ... Y cogieron otra que era apropiada de peso"... (Arg., I, 950-970).

... "Los otros se sentaron por orden en los bancos, desataron de la piedra agujereada la amarra del barco"... (Od., XIII, 75-96).

Por nuestra parte pensamos que la capacidad marinera del hippo y su operatividad era equivalente a la de las naves micénicas, capaces de realizar travesías de varios días sin recalar en tierra. Entrar por los estuarios y remontar muchos ríos. Aunque la navegación de cabotaje es más fácil y segura para estos navios que para los gauloi, afrontaban con igual eficacia la navegación de altura y nocturna. Las referencias de la Odisea son bien claras, en algunas ocasiones la travesía se prolonga durante varias jornadas sin que se interrumpa por la noche. Cuando Odiseo parte por fin después de construir su nave, ayudado por Calipso, navegará por alta mar diecisiete días:

... "Diecisiete días navegó, atravesando el mar, y al decimooctavo pudo ver los umbrosos montes del país de los feacios"... (Od., V, 265-278). 
En otra ocasión una tormenta los lleva desde Citera hasta el país de los lotófagos. Navegan durante nueve días por mar abierto, en navegación que no puede considerarse sólo de cabotaje:

... “dañosos vientos lleváronme nueve días por el ponto... y al décimo arribamos a la tierra de los lotófagos"... (Od., IX, 84-90).

La capacidad naval los hippoi puede ser comparable a las vikingas (figura 14): poco confortables, de capacidad limitada, pero ligeras, de fácil gobierno, escaso calado, útiles para remontar ríos, manejables para vararlas y dejarlas en seco con los parejos desmontados. Los asedios de las naves vikingas a las costas del Mediterráneo, e incluso a ciudades del interior comunicadas con ellas por los cauces de los ríos, es un hecho histórico bien documentado que nos ilustra la versatilidad y eficacia de estas naves ligeras. Incluso estructuralmente las naves de Gotland (Landström, 1983:57) se asemejan extraordinariamente a los hippoi: aparejos desmontables, vela cuadra, timón de espadilla en la aleta de estribor, bancadas de quita $y$ pon y carga sobre las tablas de la sentina. Salvo le montaje de las tracas del casco, que en las vikingas es al tingladillo.

\section{LA ICONOCRAFIA FENICIO PLNICA DIE I.OS HIPPOI}

La fuentes iconográficas sobre los hippoi

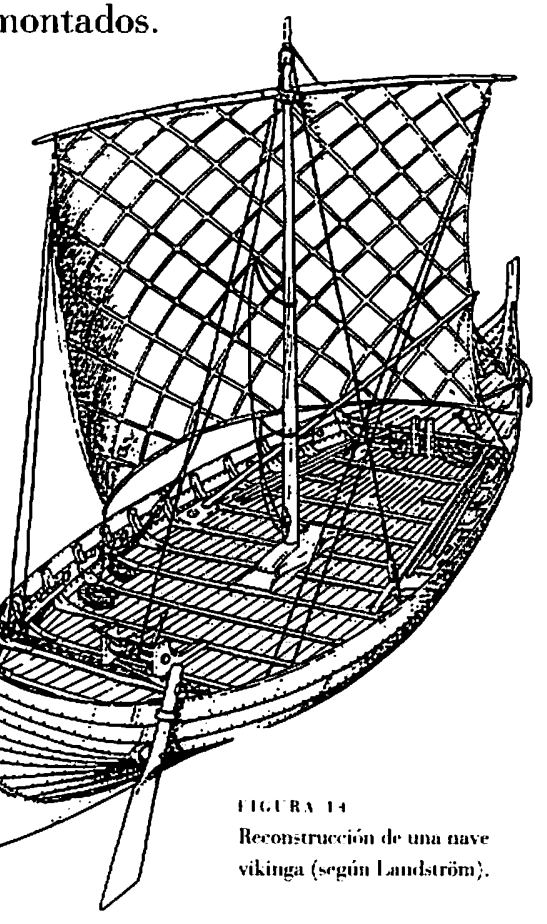
fenicios son notoriamente escasas, y las que tenemos relativamente simples, no alcanzando ni de lejos la meticulosidad y rigurosidad de las representaciones egipcias. La más antigua de las representaciones de hippoi la tenemos en los relieves (figura 11) de la puerta de bronce de Balawat, datada en el s.IX a. C. Se trata de una escena que representa la entrega de tributos por marinos fenicios en unas barcazas simétricas con cabezas de 
hippoi en la roda y el codaste. No parece que se trate del hippo clásico tal y como lo venimos entendiendo aquí para travesías marinas. Salvo que lo consideremos una representación sumamente esquemática y de escasa entidad para sacar conclusiones náuticas de interés. A nuestro juicio estamos aquí ante simples barcazas que portan el símbolo de identidad de la marina fenicia.

Una de las representaciones más conocidas y completas de hippoi fenicios la tenemos en los relieves (figura 15) del palacio de Sargon en Khorsabad, datados en el s. VIII a. C., donde se puede ver una auténtica flota de

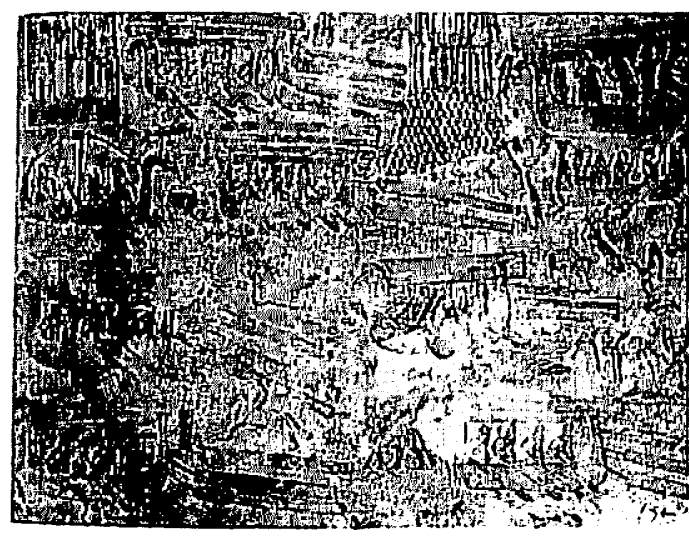

VISI R.A 1:3
Relieves de Korsulsad.

hippoi transportando troncos, bien a remolque o amarrados sobre el barco apoyados en el codaste y la roda. La arboladura está compuesta por un único mástil provisto de cofa cuadrada. De la jarcia sólo se han representado los estays y las burdas. Todos ellos navegan propulsados por los remeros, ninguno tiene las velas desplegadas. Los que van cargados de troncos tienen los aparejos desmontados, mientras que aquéllos que regresan sin carga tienen el mástil firme y amarrado por los estays y burdas citados. Creemos que constituye una magnífica evidencia de la naturaleza abatible y desmontable de todos los aparejos, lo que coincide plenamente, como ya hemos visto, con los relatos de la Odisea.

Una pintura libio-púnica (figura 16) hallada en una cueva funeraria de Kef el-Blida, en los montes Mogods (Longerstay, 1990), representa una escena funeraria en contexto náutico. Los marinos formados con sus armas en hilera junto a la borda y mirando a estribor, así como el capitán, que subido sobre la roda preside la ceremonia, rinden homenaje fúnebre al difunto, que seguramente era un miembro de la tripulación. El propio difunto aparece levitando sobre la proa de la nave. Con todo, lo que aquí nos interesa son los aspectos náuticos de la escena. La zona de la quilla y 


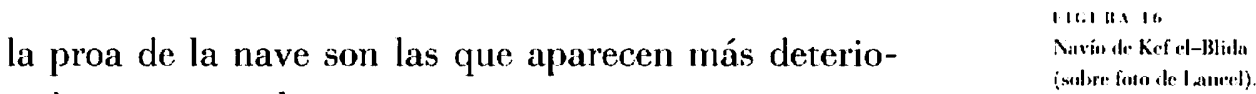
radas, pese a todo parece que estamos ante una nave relativamente panzuda, sin llegar a ser un gaulos. La nave está aparejada con mástil que soporta una vela cuadra. Son perfectamente identificables el estay y la burda, así como las brazas que descansan atadas en la parte central del mástil. Lancel (1994:210) há identificado la nave con un modelo de guerra fenicio, tal vez, dice, un eikosore. A nuestro juicio puede tratarse perfectamente de un hippo en empresa de exploración, de razia o guerra. Tampoco estamos de acuerdo en que la nave haya sido representada mientras navega. Por el contrario, detalles como las brazas amarradas, las velas sin balumas arqueadas y la actitud quieta de la tripulación que mira a alta mar por estribor son un conjunto de datos que nos indican que la nave está fondeada para celebrar la ceremonia fúnebre.

\section{EL HIPPOS CRETENSER ETRISCO Y NLRACIC:O}

A partir de diversos sellos cretenses (Marinaros, 1933) y de las pinturas de Tera (Casson, 1975; Wachsman, 1980) sabemos que la cultura minoica desarrolló una tecnología náutica variadísima con navíos adaptados a las más diferentes necesidades, desde los estrictamente ceremoniales a los de transporte. Entre los que no debían de faltar los grandes mercantes de juncos, como vemos en un sello minoico (Marinatos, 1933: $n^{\circ} 40$ ). Con todo, lo que aquí nos interesa ahora es que, al menos, durante los periodos Minoico Medio IIlb y Minoico Medio Ib (1620-1460 a. G.), es decir antes de la influencia aquea, algunos de los modelos náuticos cretenses responden a la perfección con el prototipo náutico del hippos y su perduración será igualmente larga. Las reconstrucciones (figura 17) que se han hecho (Landström, 1983:26-27) a partir de representaciones en sellos permiten identificar algunas variantes sobre un mismo modelo básico. Todas van provistas de aparejos desmontables y propulsadas por vela cuadra y remos. Sin embar- 


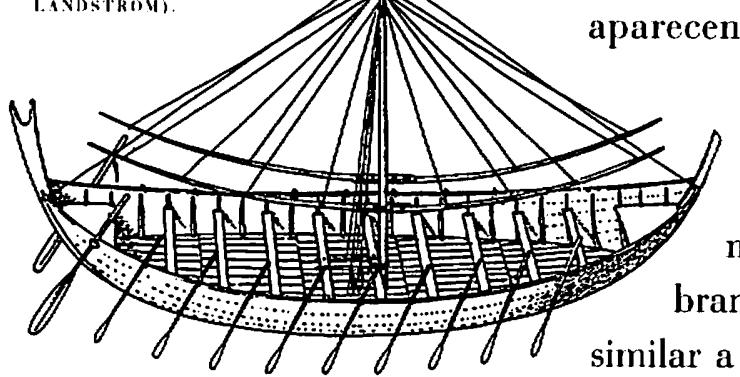

go, mientras unas han incorporado el tajamar, otras aparecen sin él. En algunas representaciones pueden identificarse muy bien la existencia de dos vergas con amantillos, otras, por el contrario, han suprimido ya la verga inferior y se maniobran con un sistema de jarcia de labor muy do. Los remos aparecen siempre sobre toletes y chu-

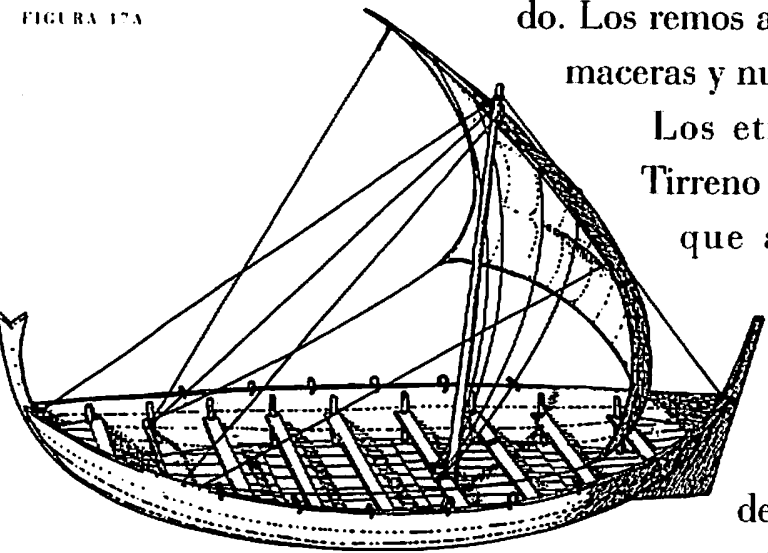

Los etruscos habían desarrollado en el Tirreno una marina local con peculiaridades que ahora no vamos a tocar (Hagy, 1986). Lo que nos interesa destacar aquí es que también un prototipo náutico equivalente en todo al hippos fenicio operaba con éxito desde al menos el s. VIII a. C.. Centraremos sólo la atención en los barcos de Novilara (Bonino: 1975), donde vemos (figura 18) una flotilla de cuatro naves, una muy incompleta a la que no nos referiremos. Todas ellas están provistas de tajamar. Dos son barcazas de escasa eslora y calado, mientras que una tercera, la que aquí nos interesa particularmente es una nave polivalente, que sigue, como hemos dicho el esquema de los hippoi. El casco es de mediano puntal y va provisto de tajamar, del que arranca un codaste lanzado hacia proa con un akroteria que no es posible de identificar con claridad. Va aparejada con un mástil y vela cuadra con relingas y refuerzos que la dividen en cuatro sectores. No sabemos si el artista confundió la jarcia mayor con la de labor (brazas), la cuestión es que lo que parecen ser brazas, por afirmarse en los penoles de la verga, acaban amarrados en proa y popa respectivamente como si fuera el estay y la burda. La tripulación parece ser la equivalente a una triacóntera, pues se pueden contar perfectamente quince remeros por banda y un capitán que dirige la opera- 


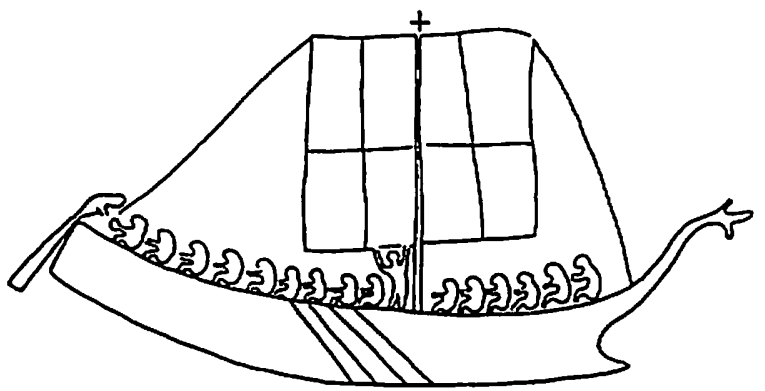

$116,1 \mathrm{kB} \mathrm{131}$

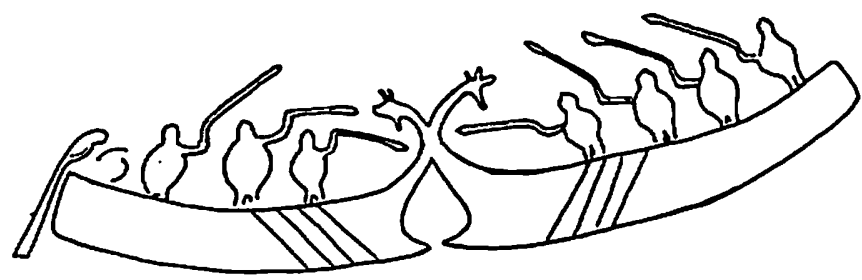

FIAIHI IBW

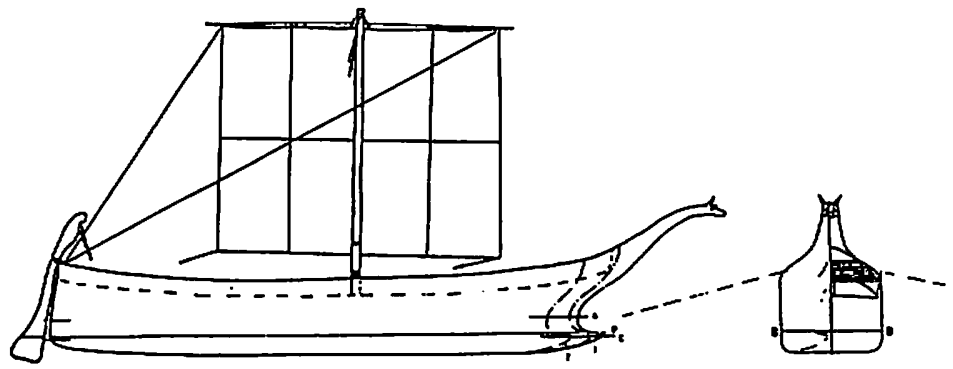

$\stackrel{0}{2}=-1$

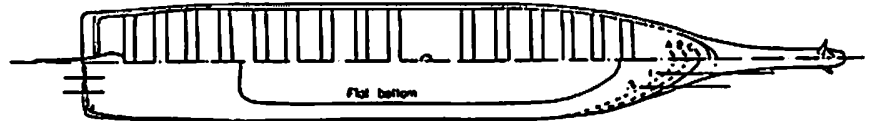

VICIRA I8C 
ción bajo el mástil. Los marineros de las naves menores parecen estar enzarzados en una trifulca con tiros de honda, por lo que podemos interpretar que en estos momentos el hippos etrusco también está en misión bélica, o por lo menos de razia. Todo lo hasta aquí dicho no desentona en absoluto de lo que hemos venido exponiendo sobre las características de este prototipo náutico. Lo que realmente tiene un interés excepcional es la presencia de un timón coaxial montado seguramente mediante un eje sobre un codaste. Por esta razón la nave no tiene el alto akrostolion que normalmente vemos en casi todas las muestras iconográficas. No importa insistir en la extraordinaria capacidad marinera que debió de desarrollar este tipo de mercante ligero etrusco con innovaciones técnicas tan importantes como el tajamar y el timón coaxial, que prácticamente no se generaliza en el Mediterráneo hasta la aparición de la carraca y la coca en la Baja Edad Media.

En la misma línea de prototipos náuticos ligeros que hemos visto en el Minóico Medio y Tardío, Micénico LH-IIIB y C, los hippoi fenicios, los sardos, cuya tradición marinera no perdieron jamás, fabricaron embarcaciones mercantes ligeras que seguían estos mismos patrones náuticos. Los conocemos relativamente bien a través de numerosa serie de ejemplares votivos de bronce (Goettlicher, 1978). El akroteria que parece identificar las naves sardas es tanto la cabeza de toro como la de ciervo (figura 19). Los navíos sardos tienen la parte central de la borda realzada con un alto escalamote calado que se apoya en la regala y soportado por perchas o postes en sus extremos. Es muy aracterístico de estas naves sardas la presencia de muchas aves posadas en los postes del escalarnote y nunca falta una posada en el extremo del mástil. Seguramente estamos ante elementos de ayuda a la orientación como ya hemos apuntado antes. Así mismo, con frecuencia cargan reses domésticas de diversas especies y en un caso carros tirados por bueyes.

A MODO DE RECAPITULACION FINAL

A lo largo de estas páginas hemos intentado una aproximación al conocimiento de dos prototipos náuticos que tanto protagonismo y papel tan 
fundamental desempeñaron en las relaciones ultramarinas de la Antigüedad mediterránea. Hemos podido comprobar que la marina cananea dispone de una notoria capacidad técnica para afrontar empresas comerciales de gran envergadura, cuestión que no era ya ningún secreto para los historiadores del Próximo Oriente. Superados los trastornos bien conocidos por las fuentes y la arqueología de fines del segundo milenio a. C., las emergentes ciudades-estado fenicias, sobre todo Sidón y Tiro, continuarán y acrecentarán la herencia de las acciones marinas iniciadas en época cananea. Seguramente los gauloi del primer milenio a. C. no son muy diferentes de los
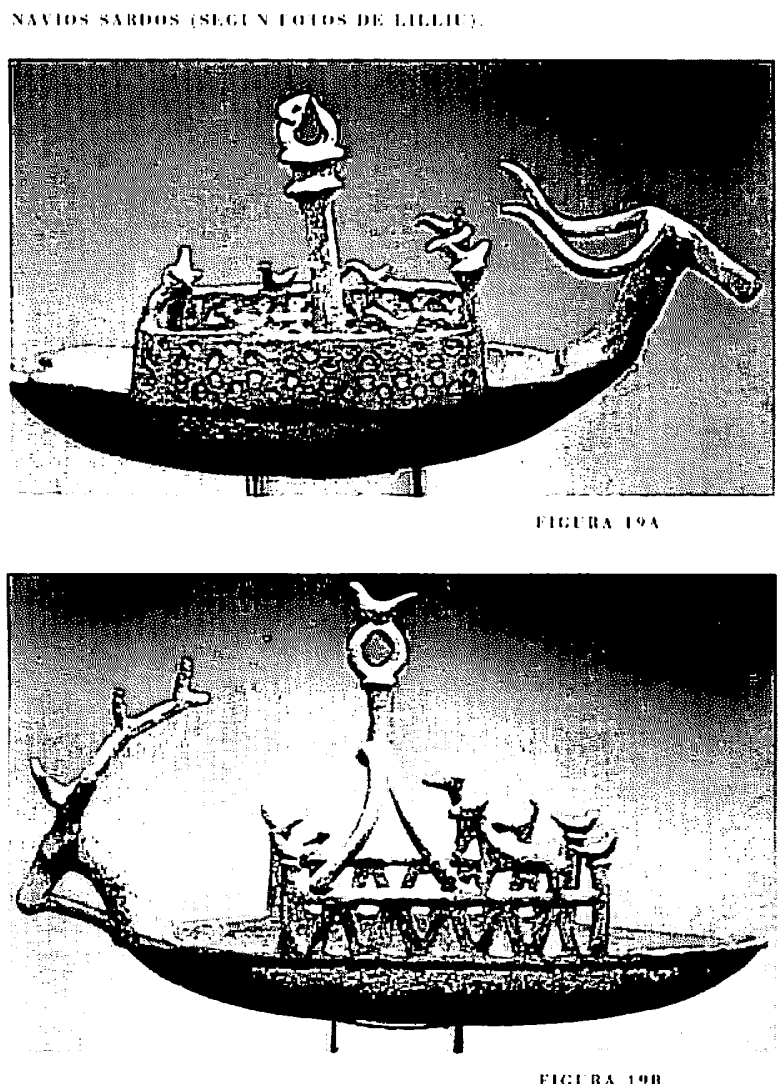

FICI BA III cananeos, aunque con toda probabilidad se introducen mejoras técnicas, como el tajamar, cuya eficacia ya se venía probando en distintas marinas, minóica, micénica y, tal vez la propia cananea, en navíos de inferior calado. Estos serán los gauloi, que muy poco después, operarán a pleno rendimiento en aguas del Estrecho de Gibraltar y la costa norteafricana.

Un prototipo náutico, aparentemente más modesto, —el hippos- con toda seguridad habría preparado el terreno en ese oscuro periodo que venimos conociendo convencionalmente como "precolonización". Los inventores de esta eficaz y versátil embarcación seguramente no los llegaremos a conocer jamás; tal vez fueron los mismos fenicios. Sin embargo, no es menos cierto que muchos otros pueblos, entre ellos cretenses y aqueos, tienen incorporadas embarcaciones muy similares a sus marinas. En cual- 
quier caso, parece fuera de toda duda que es un prototipo nacido en el contexto del Mediterráneo Oriental. En Occidente distintos pueblos indígenas debieron desarrollas importantes capacidades náuticas para las labores de redistribución regional y local de mercancías, hecho bien documentado arqueológicamente, al menos, desde el neolítico. Algo similar al prototipo hippos en Occidente no lo conocemos hasta la primera o segunda centuria del primer milenio a. C., fechas en las que los mercaderes fenicios comienzan a operar en Occidente. Por lo que la posible introducción de este tipo de embarcación entre las comunidades indígenas del Mediterráneo Central y Occidental de manos fenicias no es en absoluto descartable. Si es que antes no lo habían hecho ya los marinos micénicos. Sea como fuere, etruscos y sardos nos han dejado una buena documentación de su empleo. En la Gadir fenicia sabemos por Estrabón que era el barco más popular, empleado en muy distintas misiones marinas, tanto por las costas peninsulares, como por las norteafricanas. Los Gauloi, según este mismo autor, debían controlarlos sólo la burguesía mercantil y / o el Estado y el templo de Melkart, al fin y al cabo todos intereses muy emparentados. Tal vez también en Rusaddir constituyó la embarcación más numerosa por excelencia. En cualquier caso no podemos menospreciar el papel de los hippoi en el comercio masivo a larga distancia, como bien han puesto de manifiesto los dos barcos fenicios del s. VII a. C. de Mazarrón. 
Aletas. Parles pesteriores de los costarles del casco cue forman la curva de popa hasta el codaste. Existen por simetria dos: aleta de balour y aleta de estribor.

Amantillos. Cahos que mantienen firme y vertical el mastelero. También cabos sujetos a cada penol de las vergas y que van al mástil, cn donde pasan pror un motón que permite izar a arriar las vergas.

Amura. Parte delantera del caseo donde. romienza a estreclasse para lormar from acabamlo en la roda. Existen por simertía des: amura de babor y amura de estribor.

Aparejos. Conjume rle palos, velas y jarrias. Aphlaston. Corlaste en griegus.

Akrostolion. Roda en griego.

Akroteria. Remate de la rula, también mascarón de proa. Generalemente con forma de cabeza de un animal.

Arboladura. Conjunto de palus (o másiles), masteleros, vergas, botavaras, tangonts. perchas. elc.

Arganeo. Aro o argolla que remata la extremidad de la caña de un ancla. Por extensión, agujern por el que se pasa ol cabo que sujeta el ancla on los casos que ésta es de piedra.

Artimón. Nombre con el que lambiél se conoúa al palo de mesama y vela triangular que se guarmsin en él. Par extensión, pequeño bauprís corl un velacho cuadrado que vemos en muchas representaciones de mercantes imperinles romallus.

Babor. Parte izquierda de la nave mirándola desde popa.

Baluma. Caídas o cantos laterales de la vela cuadra.

Banda. Cada una de las dos mitades interiores del navio divididas por el eje de crujía. por simetría existen dos: bancla de habor y banda de estribor.

Baos. Piezas transversales. ligeramente curvadas que uneu las cuadernas de babor a estribor y sostienen la cubierta.

Bauprés. Palo muy inclinado hacia delante que: sale de la proa siguiendo la misma direceión. Fin los navíus antiguos podía sostemer uma pequeña vela cuadra llamada artimón.
Borda. El cano supprior del casco de ini navio. Brioles. Caula uno de las cabos quie sirven para cargar las relingas de las velas, cerrindolas a fin de: alerrarlas mejor. los de las volas cuadrats se hamen limmes en la relinga del pujamen

Brazas. Calos firmes en cada penol de la verga. Burda. Caula uno de les rabos que partiendo de lus palos se alimman a popa de aguellos.

Contrarresian las furrass que en dirección a prosa actúan solire los mismos.

Cabeceo. Mavimiento de la navo subiendoy liajando la pron por efecto del oleaje.

Cabo. Cualifuiera de las cuerdas yue se usan absirilo.

Carlinga. Pioza fija a la quilla sobre la que se asirenta el mástil.

Casco. Cinerpo del navio a exceproún de la arboladura. aparejos y pertrechos.

Casetón. Ohra de madera sifuada hacia la popa que porlía allorgar los servicios ile la nave. como la cocina y habitáculos de personajes impurtantes.

Cinca. 'lablones del liorro exterior más gruesos y reforzados coliscados de proa a popa.

Codaste. Pieza prolongación de la quilla, que: girn lacia arriba para cerrar el casco por la [i') m.

Cofa. Meseta a recepráculo en lo aleo de los pulos que permile el aromodo de un vigilanme. Permite también afianzar los obencpues y maniobrar las velas altas.

Coslado. Cincla una de las partes exteriores del rasco de proa a popa. I lay por simetría dos: costado de babor y costado de estribor.

Crujia (eje de). Plano imagimario longitudimal que divide al barco en dess mitades exactas de proa a popa y que recorre la quilla.

Caudernas. Piezas curvadas, perpendiculares a la quilla, que forman el costillaje del hareo, seportan los forros y marcan la forma del asco. Cubierta. Siselo de madera que soportado por los luos cierra la bodega del navio.

Chicote. Cada uno de los extremos o puntas de un culoo.

Chumacera. Punıo de la borda donde se ajwya el reimo. 
Durmiente. Pieza de madera que de proa a popa aguantis y refuerza la inserción de los baos por rebajo de la cubiertio.

Escala (de galo). Esculera de cuerda y travesaños de madera para diferenes usos. entre ellos subir a li rofa.

Escalamerns. Espacin contre dos Ioletes para poner el remo.

Escalamote (o falca). Tablas que se pontr de cantu subre la borda del navío.

Escotas. Calon que becho firme en los puñus bajos de las velas sirse para cazarlats.

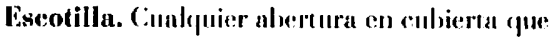
da paso al interior con bujada en vertical.

Eslora. Longitud de la nave.

Espadilla (timón de). T'imón en forma de remo que se coloca en la popan.

Espolón. Prolongación y remate de la quilla por la proa en las naves de guerra.

Estay. Caho, yue hecho firme harin proa. sujera el palo para rue no caiga hacia popa.

Estribor. Parte derecha de la nave mirándula de p'ipa a proa.

Forros. Tablas que cubren el caseo de la nave.

Falca. Ver escalamote

Flamear. Modo de ondear las velas conando el harco navega

Garrear. Dícese del hareo cuando es arratistrado por que el ancela no engancha.

Garrucho. Aro. anillo o argolla que sujeto al gratil sirve para deslizar las velas.

Gateras. Toudo orificio hertho en la cubierta o) costados para pasar caloos o remos.

Groera. Agrujero que se hace en cualquier tahlón parn el paso de algúa colo fijo o de maniolura.

Gubernaculum. Términu latino que designa el elemento de gobierno (substitutivo del timón) ron forma de gran remo. Operalsun por parejus, uno en cada ale:1a.

Gúmea. Cabo de esparto.

Jarcias. Conjunto de calros que sirven para fijar los palos (jarcia mayor) " para maniobrar las velas y aparejos (jarcia menor).

Imbornales. Agujeros practicados en la whra muera por encima del trancanil para permitir la salicla del agua que case sobre la cubierta.
Mamparo. Vombre genérico de cualquicer labique aluordo de los barcos.

Manga. Auchura del casco.

Mayor. Palo primcipral (censral) de la arboladura de un navio.

Vesana. Palu que, en las embarcaciones que lienen mis de uno, se arbola más cerea do la popa Motón. Pieza de madera denaro de la cual se sujeta una roldana o reteda con surco que acoge cl catwo y que gira sobre un perno.

Obenques. Cabos yue sujetan los palos a los trancauiles 0 a las regalas de habor y estribor.

Obra muerta. Parte del caston que emerue del ayua solve la linea de flotación.

Obra viva. Parte del casco que navega sumergida desde la línea de flonación luasta la quilla.

Pantoque. Carena del casco yue une la sección vertical ron la semiplana o plana del fonder.

Penoles. (auda uno dis los extremos de una verga. Percha. Tronco de madera que sirve para sositener algún elemento (p.e. el timón de: espadilla), o usarlo donde sea necesario.

Popa. Parte posterior del navio. Ludica también direccicin.

Proa. Purto delantera del navion. India también dirección.

Pujamen. La orilla inferior de una vela de puño a puño.

Puntal. Alura del casco descle la quilla a los baos.

Puños (de las velas). Cualcpuiera de las puntas de: una vela.

Quilla. Piszat muy resistente que constituye la mpina chorsal del navió, de la que parten las ruadernas. Finaliza en la roda por la proa y en el coolaste por la popa.

Regala. Tublón que forma el extremo silperior de la borda.

Relinga. Cada uno de los caloos con que se refuerzan las orillas de las velas.

Relingar. Coser o pegar uma relinga. Izar una vela hasta poner tirantes sus relingas de caida. Roda. Pieza prolongación de la quilla sue gira hacia arriha para rematar el casco por la proa.

Roldana. Rueda de madera sobre la que gira la 
cuerda en los motunes destinada al laboreo de: algúin calso.

Sentina. La parte más baja del interior del casco. Tajamar. Prolongación de la quilla par la proa. Tambucho. Pequeña caseta construicla sobre la cubierna para resguardarse de la intemperie. Tingladillo. Sistema de muntar las abblas del forro de forma que el extremo de la superior monte solbre la inferior.

Tolete. lije que se introduse en la regala para que sirva de asientis al remo.

Tracas. Cada hilada de tablas que forman el forro dis: una nave.

Tracas de aparadura. I as dos primeras tracas a partir de la quilla.

Trancanil. Pieza que de proa a jopa ume los extremos de los lmos por encima de la cubierta. Trinquete. Palo que, en las embaraciones que tienen más de umo, se arbola más cerca de la proa. Verga. Peroha a la cual se usigura el gratil de una vela.
AIVAR, I. (1981): La maegacium prouromana rn la Península lbérica. T'esis Doctoral. Inniv. Complutense. Madrid.

BAS(A. I. (1976): I. Havire consu de Bon-Porté. Cahiers d'Arrhóologie subaquatique, V. p. 37-42.

BASS, C. F. (1967): Cape' Gelidonya: A Bronze Age shipureck. Transactions of the American Philosophical Socieny, Philadelphia.

- (1986): A Bronze Agr: Shipwreck at Ulı Burum (Kas). $198+$ (immpaign. American Jourmal of Amheology, 90, 1986, p. 269-296.

- (1987): Splendors of the Bronze Age. Nat. Goographic, 172, n. 6, 1987, p. 69:3-733.

BASS, C. S. / FRFY, D. A. / P(I AK. C. (1984): A late Bromes: Age shipwreck at Kas. Turkey, Ineemational Joumal of Nautical Archaeology n. 13. +. 1984. 1. 271-27).

BONI.YO. M. (1965): I in modello di nave cipriota del see. VI-V a. C:., Rirista di Stusti Liguri, XXXI, "3. p. :301-310.

- (1975): The Picence shipes of lle 7th century BC: engraved at Novilara (Pesaro, laby). The International Jourmal of Nautical Archasologe; vol. 4. 11" 1, 1. 11-20

BL IIHIOI.I\%. H.G. / KARAGHORGIIS. V. (197:3): Prehistoric Cirreces and (yprus, Tulbinga.

CASSON, I. (1963): liarliest two masted ship. Archacology, 16. p. 214-219.

- (1971): Ships and seamanships in the Ancient world. Princenton.

- (1975): Bromze Age ships. The evidence of Ithera wall puintings, mtemational Joumal of Nantical Archueolog: 4. p. 3-10.

- (1980): 'I'wo-masted (ireek shij)s, Intermational Journal of Niatical Archaeology; vol. 9. n" 1. p. $68-69$.

- (1091): The ancichl Mariners, Princeton

Iniversity Press, New Jersey. 
CINTAS, P. (1948): Fomilles puminjues en Tipasa, Revue Africaine.

CORRETTI, A. (1988): Struture del commercio arcaico: le mavi, en T. HACKENS (ed.), Fortee commercio greco, cartaginese de etrusco nel Mar Tirreno, PACT-20, Ravello, p. 2+1-258.

DAVIES, N. de G. / FALILKNER, R.O. (1947): A syrian Trading venture to Egypt, Journal of Egyptian Arrhucology, 33.

DItES CUSI. l:. (1994): Aspectos técnicos de las rutas comerciales fenticius en el Mediterráneo Occidental (s. IX-VII a. (.), Archivo de Prehistoria Lerantina, XXI. p. 311-336.

FIRNAVIDEZ-MIRANDA, M. (1988): La nuvegación fenicia hacin el lejano Orridente y el Fistrecho de (Giluraltar, Congreso Internacional "Bd Estrecho de Ciburellar" (1987), Maulricl. p. +50-772.

FOLQUERLE. D. (197:3): Decouverte d'un dispositiv de signalation de la navigation untipue, Archéologia 6t, 1973, p. $67 \mathrm{y}$ sigr.

FROST. H. (1963): From Rope 1 (') Chain on the development anchors in the Mediterranean. The mariner's Mirrow, vol. 49, ॥" 1.

(GASSEND, J. V. / LIOU, B. / XIMLNES, S. (1984): L Lapave 2 de l. Ause des l aurouns. Archaeonautica. 4, 1984, p. 75-105.

(IANFRONIA, P. A. / POVIEY. P. (1981): Archeologia subrecquen, Milán.

GOL:TTLICIIISR, A. (1978): Matrrialien für rin Corpus der Sichiffsmodelle in Altertum, Mainz.

CRACE, V. (19.56): 'The Cananuile jur, en The Acgean an the Near Last studies presented to Helly Goldman. New York, p. 80-109.

GRAEVE, M.-(II. De (1981): The ships of the Ancient Near East (c. $2000-500$ 13.C.). Leuven.

GLitRRERRO, V. M., (1094): navios, $y$ naregames en las rulas de Baleares durnmte la Prehistoria, ed. El Tall. Palma.

IIACY, J. W. (1986): 800 years of Etruscan ships, The International Journal of Nautical Arrhueology; vol. 13, n" 3. P'221-250.
IIALDANL, CH. (1993): Direm evidence for organic cargoes in the Late Bronce Age, en J. OATES (eol.) Ancient Trade: New Perspectives, Wurld Archaeology, 24, n. 3, 1993, p. 348-360.

IIORNEI.I. J. (1946): The role of Birds in Early Navigation, Antiquity, 20, p. 142-149.

I.VGIIOI.T. H. (19+0): Rapport preliminaire sur scpt campagnes de fouilles à Hama Syrie (1932-35). Copenlagen.

KARACIGORGHIS, V. / GAC.NIERS, J. (1974): La céraminue chypriote de style figuré, Biblioteca de Amichiıà Ciprime, 2, Roma.

KIRK, C.S. (1949): Ships on Ceometric vases, The Ammor of the British Selwol at Alhenes, XLIV, p. 93-15:3

I.ANCFI. S. (1994): Carlago, Barcelona.

I.ANDSTRÖM. B. (1969): Sariling ships, London.

- (198:3): Bl bupur. Barcelona.

LAVIOSA. C. (1972): La marina micénica. Amnurario della scoula Archeologica di teene e delle Missione Italiame in Orimte, vol.

XI.V'II-XI.VIII. Roma, p. ?-+0.

1.ILLLII, (G. (1987): La civilà̀ murngira Sansari.

1.ONCERSTAY. M. (1990): Représentations de navires archaïques en Tunisie du Nord. Contribution a la chrronologie des haouanet, Kartage. 22. p. 33-4t.

I.LZON, J. M. / COIN, L. M. (1986): L.a navegación preastronómica en la antigiedad: utilización de los píjarus en la orientación núutica, Lacrentum, V, p. 65-85.

MARINATOS. S. P. (1933): La marime créto-mycénienne. Bulletin de Correspondance Helleniguer, 57, París, p. 170-245.

MCCASIIN. D.E.(1980): Stone andhors in Antiguity: Coastal sedllements and maritime Irade-routes in the Lastern Mediterranemu ca 1600-1050 13.C... Studies in Mediterranean Archaeologe: IXI, Cothenburg. 
MARTIN DE LA (:RUZ, J. (: (1987): Cerámicas inéditas del Bronce Final. Rerista de

Arqueología. 72, p. 50-56

- (1988): Problemas de navegación en el Estrecho de Gibraltar a finales del segundo milenio a. (... en Congreso Internacional "l:I Listrecho de Gibmaltar" (1987). Madrid, p. 357-360).

$-(1994)$ ): Los primeros contactos entre (irecia y la Península lhérica. La problemática planteada por los hallazgos de Montoro, en D. VAQLERIZO) (coord.). Arqueología de la magna Grecia. Sicilice y la Peninsula Ibérica, Córdoba, p. 111-1+6.

MELENA, J.L. (coord.) (1991): El munsto micénico, Madrid.

MOLINA. F. / PAREJA, L. (1975):

Excaraciones en la cuesta drl Negro (Purullena. (Cranada). Excavaciones Arupueológiens en España. 86, Madrid.

MORETTI, M. (1961): Targnimia: La tomba della nawe, Milán.

NEGIHLRUELA. I. (1996): L.os barcos fenicios de Mazarrón, en actas de las $X I$ Jornartes dArqueologia Fernício-Púnica, Museo Arqueológico de lbiza (en prensa).

NELSON, H. (1943): The naval batale pictured et Medine Habu. Journal of Near bastern Studies, 2, p. 40-45.

POYATO, C. / VAZQUEZ HOYS. A. M". (1989): Introduccion a la arqueologia. II milemis en el Próximo Oriente, Madrid.

PULAK, C. (1988): The Bronze Age shipwreck at Llu Burun, Turkey: 1985 campaign, American Jourmal of Arch., 92, p. 1-37.

RAMON, J. (1991): FI yacimiento fenico de Sa Caleta, en I-IV Jornadas de Arqueologia Fenicio-l'ánica, Trahajos clel Museo Aru. De: Ibiza, 24. p. 17?-196.

RESCH, W. (1967): Die Felsbilder mebiens. Line Dokumentution der ostägyptischen und nubischen Petrogbyhen, Gra\%, Austria.
ROIDAN, B. / MARTIN, M. / PIEREZ, C. (1995): El yucimiento submarino del Bajo de la Campana. Cuadernos de Arqueología Marítima, 3. 1. 11-62.

RIIPEREZ, M. S. / MIEL LENA, J. I.. (1990): I.os griegos micénicos, Madrid.

RL TZ DE ARBLIL,O, J. (1990): Rutas marítimas y colonizaciones en la Peninsula lbérica. Ina aproximación náutica a algunos problemas, Ilalica, 18, p. 79-115.

SAVCHEZ MESEGI TR. I. / FERAAYDLZ DE LA VIEGA, A I / GALAN, C. / POYATO, (: (1985): El altur de comernus de la lincantada y sus paralelos orientales. Oretum. 1. p. 125-174 SÄVli-sÖDERBRER(I), T. (1940): The moy of the Kighteenth Egyptian Dynast!: Lppsala.

- (1957): Four Ëghleemh Dymesty Tombs (Privane Tombs at Thelese), vol. I. Oxlord.

TORE. G. / ZI:LER, A. (1987): Inifa, tesori delle terra edel mare, (angliari, 1987.

TLS. V. (1972): Ancore de pietra nel Musen Vazimale di Palermo. Ilomenaje a f. Benoit. vol. I. p. 288-290, Bordightera.

VITA. J. P. (1995): El cjërcito de ligarit. (SIC: Monngrafias-1, Madrid.

WACISMANN. S. (1980): The Thera waterhorne procession reconsidered. Intrimational Journal of Ninutical Archareology, 9. p. 287-19i.

- (1981): The ships of the Sea Peoples, The International Sournal of Nautical Archaeofogy; 10.3. p. 187-20290.

- (1982): The ships of ale Sea Pouples (IINA. 10.3: 187-220): additional notes, The International Journal of Nautical Archaeology: 11. 4, p. 297-304

WIST'TERBERG, K. (198:3): Cyprole Ships fron the Bronze Age to c. 500) B.C., Cothenburg.

XEL I.A, P. (1982): Dis: Ausrüstung eines kannääischen Schiffes (KTU 4.089), Die Welt des Orients 13, Cöttingen, p. 31.35. 